\title{
DEVELOPMENT OF A METHODOLOGY TO ASSESS \\ FUTURE TRENDS IN LOW FLOWS AT THE WATERSHED SCALE USING SOLELY CLIMATE DATA
}

Étienne Foulon ${ }^{1}$, Alain N. Rousseau ${ }^{1}$, Patrick Gagnon ${ }^{2}$

1 INRS-ETE/Institut National de la Recherche Scientifique-Eau Terre Environnement, 490 rue de la Couronne, Quebec City, Quebec G1K 9A9, Canada

2 Agriculture and Agri-Food Canada, 2560 Boulevard Hochelaga, Quebec City, Quebec, G1V 2J3, Canada 
2 Low flow conditions are governed by short-to-medium term weather conditions or long term

3 climate conditions. This prompts the question: given climate scenarios, is it possible to 4 assess future extreme low flow conditions from climate data indices (CDIs)? Or should we 5 rely on the conventional approach of using outputs of climate models as inputs to a 6 hydrological model? Several CDIs were computed using 42 climate scenarios over the years 71961 to 2100 for two watersheds located in Québec, Canada. The relationship between the 8 CDIs and hydrological data indices (HDIs; 7- and 30-day low flows for two hydrological 9 seasons) were examined through correlation analysis to identify the indices governing low flows. Results of the Mann-Kendall test, with a modification for autocorrelated data, clearly 11 identified trends. A partial correlation analysis allowed attributing the observed trends in HDIs to trends in specific CDIs. Furthermore, results showed that, even during the spatial validation process, the methodological framework was able to assess trends in low flow series from: (i) trends in the effective drought index (EDI) computed from rainfall plus snowmelt minus PET amounts over ten to twelve months of the hydrological snow cover season or (ii) the cumulative difference between rainfall and potential evapotranspiration over five months of the snow free season. For $80 \%$ of the climate scenarios, trends in HDIs were successfully attributed to trends in CDIs. Overall, this paper introduces an efficient methodological framework to assess future trends in low flows given climate scenarios. The outcome may prove useful to municipalities concerned with source water management under 21 changing climate conditions.

Keywords: 


\section{Introduction}

26

27

A persistent lack of precipitation (meteorological drought) can affect soil moisture (agricultural drought) as well as groundwater and surface flows (Tallaksen and Van Lanen, 2004; Mishra and Singh, 2010), resulting in a hydrological drought and low flows. The frequency of short hydrological droughts is likely to increase due to climate change, and thus, it is expected to have a strong impact at various spatial scales (i.e., local, regional, and global scales) (Jiménez Cisneros et al., 2014). Given this context, studies around the world have looked at low flow hydrological indices (HDIs) and associated temporal variability from observed series of data (Zhang et al., 2001; Svensson et al., 2005; Ehsanzadeh and Adamowski, 2007; Khaliq et al., 2009; Fiala et al., 2010; Yang et al., 2010; Masih et al., 2011). But, as Smakhtin (2001) clearly demonstrated in his review, a clear understanding of low flow hydrology can help resource specialists manage, for example, municipal water supply, water allocations (i.e., for irrigation and industrial activities), river navigation, recreation, and wildlife conservation. Observed trends in low flows need to be explained and attributed to their underlying causes. Worldwide, there are few related studies and most of them linked trends in monthly or yearly flows to cumulative precipitation or temperature at the same temporal scale (Mavrommatis and Voudouris, 2007; Khattak et al., 2011; Ling et al., 2013; Huang et al., 2014; Li et al., 2014; Kour et al., 2016). In Canada and the USA, trends in low flow HDIs have actually been linked to specific climate data indices (CDIs) computed from cumulative rainfall, precipitation or degree-days over the course of one month up to a year (Yang et al., 2002; Burn et al., 2004a; Burn et al., 2004b; Cunderlik and Burn, 2004; Hodgkins et al., 2005; Abdul Aziz and Burn, 2006; Novotny and Stefan, 2007; Burn, 2008; Assani et al., 2011; Masih et al., 2011; Assani et al., 2012). For example, Assani et al. (2011) linked, for the south-east region of the St. Lawrence River watershed, an increase in summer 7-day low flows to an increase in summer precipitation. In the Zagros Mountains of Iran near Ghore Baghestan, Masih et al. (2011) linked a decline of the low flow conditions (1 and 7 
days minima) to a decline in precipitation during April and May. It is noteworthy that, links between HDIs and large-scale climate indices such as NAO or ENSO are beyond of the scope of this study.

All the aforementioned studies that locally linked HDIs to CDIs have relied on a statistical framework. As such, they required series of flow data to predict how changing climate conditions would affect hydrology at the watershed scale. However, it is possible to use a hydroclimatological modeling framework to anticipate this effect; combining a hydrological model and climate scenarios (Cunderlik and Simonovic, 2005; Cloke et al., 2010; CEHQ, 2013b, 2015). This approach remains challenging and cannot be readily applied by any water organization because of the required expertise. Moreover, it combines uncertainties associated with climate simulations, bias correction as well as hydrological modeling (Dobler et al., 2012; Teng et al., 2012) and the specific challenges associated with the modeling of low flows (Smakhtin, 2001; Staudinger et al., 2011).

To the best of the authors' knowledge, no study has yet investigated the potential of directly assessing HDI trends given climate scenarios. To fill this gap, this paper combines the two aforementioned frameworks in creating a statistical framework that captures past statistical relationships between CDIs and HDIs and apply the latter relationships into the future. Demonstrating the effectiveness of this novel approach required computing HDIs using a hydrological model in order to show that it worked before actually bypassing this modeling step. To ensure that the drought-inducing mechanisms were well covered and that the method was as universal as possible, the proposed methodology relied on a broad set of complementary CDIs computed for time steps varying from one day to a year using daily precipitation and minimum and maximum temperatures.

This paper is organized in four sections: (i) Material and methods, (ii) Results, (iii) Discussion, and (iv) Conclusions. The proposed methodology was developed using a case study in Québec, Canada for which: (i) future climate was built from the IPCC greenhouse gas emissions scenario SRES-A2 (Nakicenovic et al., 2000; Environnement Canada, 2010) 
for the 2001-2100 period, (ii) uncertainty of the climate change signal was addressed through the use of 42 climate simulations, and (iii) future flows were simulated using a distributed hydrological model.

\section{Materials and methods}

The organization and mapping of the Materials and methods and Results sections are introduced in Figure 1. Throughout the paper, and in accordance with CEHQ (2013a); IPCC (2013), "simulation" or "climate simulation" refers to the raw climate model outputs. "Scenario" or "climate scenario" refers to a post-processed simulation, which is a simulation for which a series of specific choices have been made (study region and period, spatial and temporal resolutions, bias-correction method). White boxes present how the climate scenarios were obtained from 42 different bias-corrected climate simulations. Grey boxes introduce the methodological framework proposed in this paper. It required computing CDIs from climate data extracted from the aforementioned climate scenarios and HDIs from simulated streamflows using a calibrated hydrological model. Afterwards, the statistical relationships between CDIs and HDIs were assessed through a correlation analysis followed by trend detection and partial correlation analyses. Black boxes refer to the results of the application of the methodological framework to a case study in Québec, Canada described in the next subsection.

Figure 1: Detailed schematic of the methodological framework and mapping of the sections of this paper. White boxes stand for the computing of climate scenarios; grey boxes refer to the Material and methods section; and the black boxes refer to the Results section.

\subsection{Case study}

\subsubsection{Study area}

Recent studies have predicted a decrease in summer flows for southern Québec, Canada (Minville et al., 2008; CEHQ, 2013b, 2015). More especially, the Yamaska River is characterized by very low flow conditions during summer, as indicated by flow records (Trudel et al., 2016). For this study, the proposed methodology was developed using two 
watersheds (Figure 2) of the St. Lawrence Lowlands (Québec, Canada): (i) Bécancour and (ii) Yamaska. They were chosen for their geophysiographical proximity and to demonstrate the application potential on: (i) an unregulated watershed and (ii) a watershed with partially regulated flows. This provided a framework well suited for comparing results and getting insights into the possibility to export the captured statistical relationships from one watershed to another.

Figure 2: Location of the study watersheds in: (a) the province of Québec and (b) the St. Lawrence River lowlands

The Bécancour River drains a 2,620-km² watershed (Labbé et al., 2011). More than half of the landscape is forested and interspersed with agriculture areas (30\%), while urban area represents $5.2 \%$ of the watershed with a population density of 25 people per $\mathrm{km}^{2}$. The population of the watershed is approximately 64,000 inhabitants and is concentrated in Thetford Mines (25,790 inhabitants in 2011) and Plessiville (6,688 in 2011). Low flows typically happen between July and September and around February while the spring flood starts in March and peak flow is often reached in April. This matches a transient snow regime (mixed rain and snow) which entails spring high flows and summer and winter low flows (Morin and Boulanger, 2005).

The Yamaska River drains a 4,784-km² watershed (Labbé et al., 2011). The watershed is mostly agricultural (52.4\%) and forested (42.8\%) while the urban area is comparable to the Bécancour watershed (3.1\%). There are 250,000 people in the watershed (52 people per $\left.\mathrm{km}^{2}\right)$ mostly concentrated in Granby $(66,000$ inhabitants in 2014$)$, Saint-Hyacinthe $(54,500$ inhabitants in 2014) and Cowansville (13,000 inhabitants in 2015). Low flows typically occur at the same time as those of the Bécancour watershed.

St. Hyacinthe and Rivière Noire, two towns located in the Yamaska watershed, have had to deal with a critical water availability problem one year out of five (based on the 1971-2000 period). For the 2041-2070 time period, Côté et al. (2013) indicated that in all likelihood it would be the case one year out of two. Since water shortages are likely to occur in other 
132 towns throughout Quebec and elsewhere in the world, therefore, robust tools that do not 133 require hydrological modeling and could be readily used by any water utility organization are 134 needed.

\subsubsection{Hydrological seasons}

Temporal changes in the hydrology of a watershed can be accounted for through the definition of "hydrologic seasons"; dividing the year into distinct time periods of similar conditions (Curtis, 2006). Two hydrological seasons were defined according to climate variability and signal characterizing the length of the study period (1961-2100): (i) a snowfree (SF) season, and (ii) a snow-cover (SC) season. They were defined in terms of snow water equivalent (SWE) according to the following rules. SC season starts on the first day $d$ beyond August that satisfies the following condition:

$S W E_{d} \geq 10 \mathrm{~mm} \&\left(S W E_{j+1}-S W E_{j}\right) \geq 0$ for all $j \in[d ; d+7]$

Namely, the SWE needs to be greater than $10 \mathrm{~mm}$ and increasing for at least eight consecutive days for the SC season to begin. The SC season ends on the first day $d$ that meets the following condition:

$$
\boldsymbol{S} \boldsymbol{W} \boldsymbol{E}_{\boldsymbol{d}}<10 \mathrm{~mm} \&\left(\boldsymbol{S} \boldsymbol{W} \boldsymbol{E}_{\boldsymbol{j}+1}-\boldsymbol{S} \boldsymbol{W} \boldsymbol{E}_{\boldsymbol{j}}\right) \leq \mathbf{0} \text { for all } \boldsymbol{j} \in[\boldsymbol{d} ; \boldsymbol{d}+7]
$$

Namely, the SWE is less than $10 \mathrm{~mm}$ and decreasing for at least eight consecutive days. The SF season starts on day $d+1$. If the SF season does not end before the calendar year, it continues onto the next one until conditions are met for the SC season to start, meaning that some years, especially in the future, may not have a SC season. The SWE threshold value $(10 \mathrm{~mm})$ and the number of consecutive days (8 days) were selected after sensitivity tests (included in supporting material 1). In more mountainous regions such as the Alps or the Rocky Mountains, these two parameters would need to be calibrated to reflect local hydrological processes and to differentiate low flows during the ice cover period from the open water period. Rousseau et al. (2014) and Klein et al. (2016) also chose a 10-mm threshold to assess whether a precipitation event was occurring in summer/fall (SWE $<10 \mathrm{~mm}$ ) or in spring (SWE>10mm). 


\subsection{Climate simulations}

160 To investigate the effect of global warming on low flows, two IPCC greenhouse gas

161 emissions scenarios were used: "observation of the $20^{\text {th }}$ century" for the 1961-2000 period 162 and SRES-A2 (Nakicenovic et al., 2000; Environnement Canada, 2010) for the 2001-2100 163 period. The A2 emission scenario was used because observations of $\mathrm{CO}_{2}$ atmospheric 164 global emissions are at the high end of the plausible IPCC SRES emissions projections 165 (Raupach et al., 2007; Rousseau et al., 2014). The selected simulations represented 42 of 166 the 87 original simulations from a climate ensemble called (cQ) ${ }^{2}$ and produced by the 167 Ouranos consortium (Guay et al., 2015). They consisted of simulations from the World 168 Climate Research Programme phase 3 (CMIP3) (Meehl et al., 2007a), the North American 169 Regional Climate Change Assessment Program (NARCCAP) (Mearns et al., 2012), and the 170 Canadian Regional Climate Model (CRCM) (Music and Caya, 2007; de Elia and Côté, 2010; 171 Paquin, 2010) operational runs supplied by Ouranos. The 42 simulations introduced in Table 1721 are based on 14 global climate model (GCM) runs with different initial conditions (one to

173 five members) and four different regional climate models (RCMs). They were selected to 174 avoid dependencies between models while covering all sources of climate uncertainty apart 175 from the emissions scenario uncertainty (Hawkins and Sutton, 2011), which is discussed 176 later on. 
Table 1: Description of the 42 climate simulations extracted from the (cQ) ${ }^{2}$ project and generated by CRCM version 4

\begin{tabular}{ccccc} 
& \#Simulation & \#GCM & \#RCM & SRES \\
\cline { 2 - 5 } CMIP3 $^{a}$ & 23 & 12 & 0 & A2 \\
NARCCAP $^{b}$ & 8 & 3 & 3 & A2 \\
OURANOS $^{c}$ & 1 & 1 & 1 & A2 \\
OURANOS $^{*}$ & 10 & 2 & 1 & A2
\end{tabular}

åCM used: BCCR_BCM2.0; CSIRO_MK3.0; CSIRO_MK3.5; CCCMA_CGCM3.1; GFDL_CM2.0; CNRM_CM3; IPSL_CM4; INGV_ECHAM4; ECHAM5; MIUB_ECHO_G; MIROC3.2_MEDRES; MRI CGCM2.3.2a

${ }^{\mathrm{b}} \mathrm{GCM}$ used : CCSM; HADCM3; CCCMA_CGCM3.1; GFDL_CM2.0. RCM used: HRM3; RCM3; WRFG 'GCM used:CNRM_CM3. RCM used: CRCM4

*Simulations generated by the CRCM4 that cover 1961 to 2100 continuously (GCM used: CCCMA_CGCM3.1; ECHAM5)

Simulation data were corrected using the daily translation method (Mpelasoka and Chiew, 2009) which is a quantile-quantile mapping technique removing the bias of climate model outputs. The temperature correction is additive while the correction for precipitation is multiplicative. The reader is referred to the following publications for more details (Wood et al., 2004; Lopez et al., 2009; Mpelasoka and Chiew, 2009; Guay et al., 2015). This method conserves the different characteristics and dynamics of each individual climate model. Each climate simulation has a temporal sequence of meteorological events which are different between member simulations. The post-processing method assumes the biases to be of equal magnitude in the future and reference periods; that is the relationship between simulated and observed data is still applicable in the future (Huard, 2010). The reference period 1961-2000 and observed precipitation data came from a 10-km grid covering southern Canada, that is south of $60^{\circ} \mathrm{N}$ (Hutchinson et al., 2009) averaged on the RCM or GCM grid before application of the bias correction methodology. Finally, besides the ten simulations supplied by Ouranos covering the 1961-2100 period continuously, other simulations (32) were available for two temporal horizons: (i) the past horizon (1971-2000) and (ii) future horizon (2041-2070). As a consequence, the following methods and results are presented for two temporal horizons. 


\subsection{Climate data indices - CDls}

204 Daily precipitation and minimum and maximum temperatures at two meters of elevation were 205 retrieved, from the climate scenarios (Figure 1). Table 2 introduces the CDIs used in this 206 study; they were taken from the literature based on their widespread use, data requirements, 207 and potential to corroborate (assessed through linear correlation coefficients) with low flow 208 HDIs. The CDIs are divided into four categories with respect to the type of input data needed 209 for their computation, that is computed from: (i) precipitation data, (ii) temperature data, (iii) 210 blended data (both precipitation and temperature), and (iv) drought indices formulas. Other 211 CDIs could be included if other HDIs were to be studied, illustrating the flexibility of the 212 methodology being developed in this paper. The CDIs used are computed starting on the day 213 of occurrence of each individual HDI and continuing backward in time, providing a framework 214 for future work on forecasting extreme flow conditions. 


\begin{tabular}{|c|c|c|}
\hline $\begin{array}{l}\text { Input Variable } \\
\text { Category }\end{array}$ & CDI Groups 1-15 & Sources \\
\hline $\begin{array}{l}\text { Precipitation } \\
\text { data }\end{array}$ & $\begin{array}{l}\text { 1. Cumulative rainfall, snowfall, and } \\
\text { precipitation amounts ( } 3 \text { CDIs) }\end{array}$ & $\begin{array}{c}\text { Zaidman et al. (2001); Yang et al. (2002); Hodgkins } \\
\text { et al. (2005); Lang Delus et al. (2006); de Wit et al. } \\
\text { (2007); Assani et al. (2011); Tian et al. (2011); Ge } \\
\text { et al. (2012); Souvignet et al. (2013) }\end{array}$ \\
\hline \multirow{2}{*}{$\begin{array}{l}\text { Temperature } \\
\text { data }\end{array}$} & $\begin{array}{l}\text { 2. Minimum, mean, and maximum } \\
\text { temperatures ( } 3 \text { CDIs) }\end{array}$ & $\begin{array}{c}\text { Yang et al. (2002); Hodgkins et al. (2005); de Wit et } \\
\text { al. (2007); Engeland and Hisdal (2009); Ge et al. } \\
\text { (2012) }\end{array}$ \\
\hline & $\begin{array}{l}\text { 3. Cumulative freezing degrees, } \\
\text { cumulative degrees above } 0^{\circ} \mathrm{C} \text {, } \\
\text { maximum and cumulative temperature } \\
\text { since last snowfall ( } 4 \text { CDIs) }\end{array}$ & $N A$ \\
\hline \multirow[b]{3}{*}{ Blended data } & 4. PET (1 CDI) & Assani et al. (2011) \\
\hline & 5. Climatic demand (R-PET) (1 CDI) & $\begin{array}{l}\text { Paltineanu et al. (2007); Paltineanu et al. (2009); } \\
\text { Institution Adour (2011) }\end{array}$ \\
\hline & $\begin{array}{l}\text { 6. Snowpack depth, snowmelt }(1 \mathrm{CDI}) \\
\text { 7. Snowmelt and rainfall amounts } \\
(1 \mathrm{CDI}) \\
8 . \text { Snowmelt and rainfall minus PET } \\
\text { amounts (1 CDI) }\end{array}$ & Girard (1970) \\
\hline \multirow{5}{*}{$\begin{array}{l}\text { Drought } \\
\text { Indices }\end{array}$} & 9. Z score (1 CDI) & Giddings et al. (2005) \\
\hline & 10. SPI (1 CDI) & $\begin{array}{c}\text { McKee et al. (1993, 1995); Roudier (2008); Liu et } \\
\text { al. (2012) }\end{array}$ \\
\hline & 11. EDI (1 CDI) & Byun and Wilhite (1999) \\
\hline & $\begin{array}{l}\text { 12. EDI computed from rainfall and } \\
\text { snowmelt amounts ( } 1 \mathrm{CDI}) \\
13 . \text { EDI computed from climatic demand } \\
\text { (1 CDI) } \\
14 \text {. EDI computed from rainfall and } \\
\text { snowmelt minus PET amounts ( } 1 \mathrm{CDI})\end{array}$ & $N A$ \\
\hline & 15. PDSI (1 CDI) & Palmer (1965); Choi et al. (2013) \\
\hline
\end{tabular}

$R$ stands for rainfall, $P E T$ for Potential evapotranspiration, $S P I$ for standardized precipitation index, EDI for effective drought index, $P D S /$ for Palmer drought severity index.

218 The PDSI and SPI are two normalized drought indices that allow detection of dry as well wet 219 periods. The PDSI is a cumulative index, computed on a monthly basis (Heddinghaus and 220 Sabol, 1991) and has been linked to monthly flows $(r=0.83, p<0.01)$ by Choi et al. (2013). 221 The SPI assesses short term water supply deficit or surplus as well as long-term 222 groundwater supplies. It is computed as a rainfall departure (Wilhite and Glantz, 1985; Liu et 223 al., 2012) from any timescale. The climatic demand computes the difference between 224 precipitation and PET (thus in the blended data type). In Romania, it has been combined to 225 the SPI to identify water quantity issues (Paltineanu et al., 2007). The EDI is a drought 226 recursive index based on the effective precipitation concept (Byun and Wilhite, 1999). It 
227 takes into account antecedent rainfall conditions and is computed on a daily basis while 228 accounting for past (from 15 to 365 days) rainfall amounts with a decreasing weight. 229 Because it does not consider any location or climate characteristics, it can be used anywhere 230 (Roudier, 2008; Akthari et al., 2009; Deo et al., 2016).

231 Except for the Z score which is conceptually equivalent to the SPI (standardized anomaly of 232 the precipitation), the SPI, and the PDSI that were computed on a monthly basis, the CDIs 233 introduced in Table 2 were all computed for 18 time steps starting on the day of occurrence 234 of each individual HDI and going backward in time (one to six days, one to three weeks, one 235 to six months, eight, ten and twelve months).

\section{$236 \quad 2.4$ Hydrological model}

237 In this paper, HYDROTEL is the hydrological model calibrated from observed data and used 238 to generate the series of past and future HDIs (Figure 1). It is a process-based, continuous, 239 semi-distributed hydrological model (Fortin et al., 2001; Turcotte et al., 2003; Turcotte et al., 240 2007; Bouda et al., 2012; Bouda et al., 2014), and currently used for inflow forecasting by 241 Hydro-Quebec, Quebec's major power utility, and the Quebec Hydrological Expertise Centre 242 (CEHQ). It was designed to use available remote sensing and GIS data at either a 3-h or a 243 daily time step. It is based on the spatial segmentation of a watershed into relatively 244 homogeneous hydrological units (RHHUs, elementary subwatersheds or hillslopes as 245 desired) and interconnected river segments (RSs) draining the aforementioned units. A semi246 automatic, GIS-based framework called PHYSITEL (Turcotte et al., 2001; Rousseau et al., 247 2011; Noël et al., 2014) allows easy watershed segmentation and parameterization of the 248 hydrological objects (RHHUs and RSs). The model is composed of six computational 249 modules, which run in successive steps. Each module simulates a specific hydrological 250 process and the reader is referred to Fortin et al. (2001) and Turcotte et al. (2007) for more 251 details on these aspects of HYDROTEL. 


\subsubsection{Calibration and validation}

253 The main calibration parameters of HYDROTEL can be grouped (Table 3) into snow 254 parameters, soil parameters, and interpolation coefficients for temperature and precipitation. 255 Interpolation is computed as the average of the three nearest meteorological stations 256 weighted by the square of the inverse distances between a RHHU and the stations 257 (Reciprocal-Distance-Squared method).

Table 3: HYDROTEL key parameters

\begin{tabular}{|c|c|c|}
\hline Type & Parameters & Units \\
\hline \multirow{9}{*}{$\begin{array}{l}\text { Snow } \\
\text { parameters }\end{array}$} & Melt factor for evergreen forests & $\mathrm{mm} / \mathrm{d} .{ }^{\circ} \mathrm{C}$ \\
\hline & Melt factor for deciduous forests & $\mathrm{mm} / \mathrm{d} .{ }^{\circ} \mathrm{C}$ \\
\hline & Melt factor for open areas & $\mathrm{mm} / \mathrm{d} .{ }^{\circ} \mathrm{C}$ \\
\hline & Threshold air temperature for melt in & ${ }^{\circ} \mathrm{C}$ \\
\hline & evergreen forests & \\
\hline & $\begin{array}{l}\text { Threshold air temperature for melt in in } \\
\text { deciduous forests }\end{array}$ & ${ }^{\circ} \mathrm{C}$ \\
\hline & $\begin{array}{l}\text { Threshold air temperature for melt in open } \\
\text { areas }\end{array}$ & ${ }^{\circ} \mathrm{C}$ \\
\hline & Melt rate at the snow-soil interface & $\mathrm{mm} / \mathrm{d}$ \\
\hline & Compaction coefficient & - \\
\hline \multirow{7}{*}{$\begin{array}{l}\text { Soil } \\
\text { parameters }\end{array}$} & Potential evapotranspiration multiplying factor & - \\
\hline & Depth of the lower boundary of soil layer \#1 & $\mathrm{m}$ \\
\hline & Depth of the lower boundary of soil layer \#2 & $\mathrm{m}$ \\
\hline & Depth of the lower boundary of soil layer \#3 & $\mathrm{m}$ \\
\hline & Recession coefficient & $\mathrm{m} / \mathrm{h}$ \\
\hline & Extinction coefficient & - \\
\hline & Maximum variation of humidity & - \\
\hline \multirow{2}{*}{$\begin{array}{l}\text { Interpolation } \\
\text { coefficients }\end{array}$} & $\begin{array}{l}\text { Threshold air temperature for partitioning } \\
\text { solid and liquid precipitation }\end{array}$ & ${ }^{\circ} \mathrm{C}$ \\
\hline & $\begin{array}{l}\text { Precipitation vertical gradient } \\
\text { Temperature vertical gradient }\end{array}$ & $\begin{array}{l}\mathrm{mm} / 100 \mathrm{~m} \\
{ }^{\circ} \mathrm{C} / 100 \mathrm{~m}\end{array}$ \\
\hline
\end{tabular}

261 Using the methodology introduced by Turcotte et al. (2003), manual calibration and validation of HYDROTEL was performed over five-year-periods according to available observed climate 263 data provided by the CEHQ for each subwatershed over the 1990-2010 period. As reported 264 by Bouda et al. (2014), when compared with an automatic calibration, the structured, trial265 and-error, procedure proposed by Turcotte et al. (2003) can achieve very similar 266 performances. Indeed, Bouda et al. (2014) have shown that automatic calibration could 267 provide a marginal improvement over manual calibration (less than $4.2 \%$ in terms of Nash268 Sutcliff Efficiency, NSE). This manual calibration used both NSE and RMSE $\left(\mathrm{m}^{3} / \mathrm{s}\right)$ as 
objective functions. The modeling performance for low flows was assessed using the Nash-

$270 \log$ (NSE computed from log transformed flows) objective function which is acknowledged as

271 the best objective function for low flow modeling (Krause et al., 2005). In each case, a one-

272 year spin up was used to minimize initialization errors. Observed climate data were 273 computed on a grid (a 28- and 52-point grid for the Bécancour and Yamaska watersheds, 274 respectively) by isotropic kriging following the method described in Poirier et al. (2012) using 275 data collected through the Climate Surveillance Program of the minsitère du Développement 276 durable, de l'Environnement et de la Lutte contre les changements climatiques (MDDELCC). 277 Flow data were extracted from the CEHQ data base (CEHQ, 2012) that includes around 230 278 hydrometric stations throughout Quebec.

279 The Bécancour and Yamaska watersheds were respectively divided into 1813 and 1299 280 hillslopes a.k.a. RHHUs with mean areas of 143 ha and 369 ha and 736 and 513 river 281 segments with mean lengths of 1885 and $3475 \mathrm{~m}$ (excluding lakes), defining three regions of 282 interest for parametrization. These regions were used to define local parameter sets of 283 consistent values for the calibration of HYDROTEL. The discretization of both watersheds 284 provided a good representation of the spatial heterogeneity of the landscape while allowing 285 for a reasonable computational time. Three specific river segments and hydrological stations 286 (see Figure 3) were selected for the calibration and validation of each watershed.

Figure 3: (a) Bécancour and (b) Yamaska parametrization regions and hydrological stations used for the 288 calibration and validation of HYDROTEL. Red, green, and blue colors stand for upstream, median, and 289 downstream subwatersheds, repectively. \# indicates the gauging stations reference number.

290 Data from these stations (\#24003, \#24014, \#24007, and \#30302, \#30304, \#30345 for 291 Bécancour and Yamaska, respectively) were deemed suitable for this study because they 292 are all validated (except for the current year), readily available, and used in hydrological and 293 hydroclimatic impact studies (CEHQ, 2013b; Rousseau et al., 2013; Rousseau et al., 2014; 294 CEHQ, 2015; Fossey and Rousseau, 2016a; Klein et al., 2016; Trudel et al., 2016). 295 Measured flows on the Bécancour watershed are natural while they are partly regulated on 296 the Yamaska watershed. The impact of this regulation will be discussed later on. 


\subsubsection{Computation of the hydrological data indices - HDls}

298 The HDls considered in this paper are the seasonal ${ }_{7 d} Q_{\min }$ and ${ }_{30 d} Q_{\min }$, which refer to the 299 seasonal minimum of the 7 and 30 consecutive-day moving average flow, respectively. 300 These HDIs were selected because the MDDELCC uses $Q_{2-7}$ (2-year annual minimum of the 3017 consecutive-day average flow) to assess whether water can be abstracted from a specific 302 source (MDDELCC, 2015). Also, the MDDEP uses the $Q_{10-7}$, or $Q_{2-7}$, to evaluate the 303 exceedance of water quality criteria for the assessment of pollutant discharge permits 304 (MDDEP, 2007).

305 Once calibrated, the semi-distributed hydrological model HYDROTEL was used to generate 306 past and future seasonal HDIs (for each of the 42 selected climate scenarios) as shown in 307 Figure 1, with the parameter values computed during the calibration/validation process. 308 Indeed, we assumed a similar quality of model responses to future conditions as for the bias 309 correction method for climate models. Precipitation and minimum and maximum 310 temperatures came from the climate scenarios. They were extracted from the nearest ten 311 grid-points of the watershed boundaries before using a Thiessen polygon routine to compute values for each RHHU.

313 To further characterize the capacity of HYDROTEL to simulate flows inducing the observed 314 HDIs, the latter were plotted against HDIs calculated using the calibration/validation dataset. 315 The HDls computed using the 42 climate scenarios were used to assess the capacity of 316 these selected scenarios to encompass observed values.

\subsection{Assessing HDls from CDIs}

318 2.5.1 Conditions governing low flows - Correlation analysis

319 Pearson as well as Spearman correlation coefficients were calculated to assess the 320 relationships between the four series of seasonal $\mathrm{HDIs}\left({ }_{7 d} \mathrm{Q}_{\min }\right.$ and ${ }_{30 \mathrm{~d}} \mathrm{Q}_{\min }$ for the $\mathrm{SC}$ and $\mathrm{SF}$ 321 seasons) and the associated CDIs (Table 2). For this study, the post-processing method is 322 based on the following assumptions: (i) the relationships between simulated and observed 323 data for the past-period (1971-2000) will still be applicable in the future (2041-2070); and (ii) 
324 the calibrated parameter values are valid over the future time horizon as well. For sake of 325 consistency, a similar assumption was made regarding the relationship between HDIs and 326 CDIs, but verified through what can be seen as a calibration and validation phase of the 327 correlation analysis as is done for hydrological models. The Wilcoxon rank-sum test (Mann 328 and Whitney, 1947) was applied to test whether median correlations between HDIs and CDIs 329 were statistically different between past and future temporal horizons. The validity of these 330 assumptions from the perspective of climate conditions as well as land use and land cover is 331 examined in details in the discussion section of this paper.

332 In short, for each one of the 15 CDI groups introduced in Table 2 and each of the 42 climate 333 scenarios, correlation coefficients were computed individually for each HDI and each season. 334 Then, the best median correlations (maximum absolute median value of the correlation 335 coefficients) for the four CDI categories introduced in Table 1 were identified along with the 336 frequency at which they occurred. Afterwards, the statistical relationships were validated over 337 the future temporal horizon. To account for the fact that many CDIs were tested against each $338 \mathrm{HDI}$ and that correlations could be due to chance, a bootstrap resampling method based on 339 Monte Carlo simulations was applied (Livezey and Chen, 1983) to every CDI-HDI couples as 340 follows:

341 (i) A year was randomly selected from the temporal horizon of interest (past or $342 \quad$ future).

343 (ii) The paired value (CDI-HDI) for the selected year was added to the resampled 344 data set.

345 (iii) Steps (i) and (ii) were repeated until the resampled data set had the required 346 number of years of data. The required number was set equal to the number of

348 (iv) The correlation computation was applied to resampled data set and the result was 349 saved. 
350 Steps (i) to (iv) were repeated 1000 times, resulting in a distribution of the correlation 351 coefficients computed from the 1000 resampled data set. The distribution allowed for the 352 determination of the confidence interval $(\mathrm{Cl})$ of the correlation coefficient computed from the 353 initial set of data (typically 90 or $95 \% \mathrm{Cl}$ ). If the $\mathrm{Cl}$ minimum was greater than 0 , the correlation was then statistically significant.

\subsubsection{HDI trends and governing drivers - trend detection and partial correlation analysis}

Long term linear trends were analyzed using the non-parametric rank-based Mann-Kendall test (Kendall, 1938; Mann, 1945; Kendall, 1975; Gilbert, 1987) for the four series of HDls and the associated CDIs obtained through the correlation analysis. The Mann-Kendall (MK) test has been widely used to detect a trend in hydroclimatic time series (Lettenmaier et al., 1994; Lins and Slack, 1999; Douglas et al., 2000; Zhang et al., 2000; Zhang et al., 2001; Yue and Wang, 2002; Novotny and Stefan, 2007; Li et al., 2009). The test is based on the null hypothesis that a sample of data is independent and identically distributed. The alternate hypothesis is that a trend exists in the data. To get more details about this test, the reader is referred to the previous references and especially that of Novotny and Stefan (2007). In the presence of serial correlation or autocorrelation, the assumption of serial independence is violated. The existence of positive serial correlation increases the probability that the MK test detects a trend when none exists (von Storch, 1999), whereas a negative autocorrelation makes it too difficult to find a significant trend (Hamed and RamachandraRao, 1998; Yue and Wang, 2002).The MK test can be modified to obtain the true variance of the MK correlation under the autocorrelation structure displayed by the data (Hamed and RamachandraRao, 1998). Tests were conducted for each series of HDls and CDIs as well as both temporal horizons using the modified MK test to account for autocorrelation.

Partial correlations were calculated between each HDI and associated CDIs while controlling for the time step variable. This allowed for the identification of the correlation between variables independent of any common temporal trend signal and for the attribution of the 
377 observed trends in HDls to trends in CDls (Burn et al., 2004a; Burn, 2008). As for the 378 correlation analysis described in the previous sub-section, trends, especially when they are 379 analyzed for the same CDI-HDI couple for 42 different climate scenarios can be due to 380 chance. Livezey and Chen (1983) indicated the need to consider field-significance of the outcomes of a set of statistical tests. It accounts for the observed cross-correlation in the 382 data for a collection of locations (which in our case was a collection of temporality or climate 383 scenarios) and allows for the determination of the percentage of tests that are expected to 384 show a trend, at a local given significance level, purely by chance. The bootstrap resampling 385 method based on Monte Carlo simulations was thus applied for each scenario following the steps described in the previous subsection except for the fourth step that became:

(iv) The Mann-Kendall test was applied to the data from each scenario in the resampled data set and the percentage of results that were significant at the $\alpha$ significance level was determined; $\alpha$ being the local significance level (typically 5 or $10 \%)$

Steps (i) to (iv) were repeated 1000 times resulting in a distribution of the percentage of 392 results that were significant at the $\alpha$ level. From this distribution, the value that was exceeded $\beta \%$ of the time (typically 5 or $10 \%$ ) was selected as the critical value. $\beta$ is referred to as the global significance level. This method was similarly applied in Burn and Hag Elnur (2002); Burn et al. (2004b) and discussed in details in Renard et al. (2008).

\section{Results}

\section{$397 \quad 3.1 \quad$ Hydrological model}

398 This subsection illustrates using the calibration and validation results the capacity of the 399 model to: (i) represent flows in general and low flows in particular and (ii) produce a 400 distribution of HDIs that includes at best the observed values. Presentation of climate data 401 characteristics was beyond the scope of this paper; as such it can be found in supporting 402 material 2. 


\subsubsection{Calibration and validation results}

404 Model performances for calibration and validation periods of the two study watersheds are 405 given in Table 4. For each river segment, according to the hydrologic model performance 406 rating of Moriasi et al. (2007), the results provide a "good fit" (NSE>0.65) between observed 407 and simulated flows and even a "very good fit" for most of the results (NSE>0.75). Nash-log 408 values vouch for the good representation of low flows with values ranging from 0.65 to 0.70 409 and 0.74 to 0.78 for the calibration period for the Bécancour and Yamaska watersheds, 410 respectively. There is no clear decline in performances between the calibration and validation 411 periods, most even increase between the two periods. This validates the choice of calibration 412 parameters as highlighted in Beven (2006). More especially, Nash-log values are larger for 413 the validation period and range from 0.72 to 0.77 and from 0.72 to 0.76 for the Bécancour 414 and Yamaska watersheds, respectively.

Table 4: Model performance for the calibration and validation periods

\begin{tabular}{lcccccccc}
\hline $\begin{array}{c}\text { River } \\
\text { segment }\end{array}$ & $\begin{array}{c}\text { Calibration } \\
\text { period }\end{array}$ & NSE & $\begin{array}{c}\text { Nash- } \\
\text { log }\end{array}$ & $\begin{array}{c}\text { RMSE } \\
\left(\mathbf{m}^{3} \cdot \mathbf{s}^{-1}\right)\end{array}$ & $\begin{array}{c}\text { Validation } \\
\text { period }\end{array}$ & NSE & $\begin{array}{c}\text { Nash- } \\
\text { log }\end{array}$ & $\begin{array}{c}\text { RMSE } \\
\left(\mathbf{m}^{3} \cdot \mathbf{s}^{-1}\right)\end{array}$ \\
\hline Béc TR-255 & $2005-2010$ & 0.76 & 0.70 & 14.7 & $2000-2005$ & 0.86 & 0.77 & 10.0 \\
Béc TR-102 & $2005-2010$ & 0.67 & 0.65 & 34.5 & $2000-2005$ & 0.72 & 0.75 & 30.1 \\
Béc TR-70 & $1995-2000$ & 0.76 & 0.65 & 30.8 & $1990-1995$ & 0.76 & 0.72 & 31.8 \\
Yam TR-240 & $2005-2010$ & 0.76 & 0.77 & 16.9 & $2000-2005$ & 0.74 & 0.72 & 14.4 \\
Yam TR-63 & $2005-2010$ & 0.68 & 0.74 & 27.1 & $2000-2005$ & 0.71 & 0.72 & 21.4 \\
Yam TR-61 & $2005-2010$ & 0.77 & 0.78 & 47.1 & $2000-2005$ & 0.77 & 0.76 & 39.0 \\
\hline
\end{tabular}

\subsubsection{Computation of the HDls}

418 The capacity of HYDROTEL to correctly reproduce the HDIs was assessed for the river 419 segments with observed values closest to the outlet of the study watersheds that is TR-70 420 and TR-61 for the Bécancour and Yamaska watersheds, respectively. Figure 4 and Figure 5 421 introduce the boxplots of the seasonal HDls computed using the results of the hydrological 422 modeling of the climate scenarios (post-processed simulations) for the Bécancour and 423 Yamaska watersheds, respectively. Figure 4 shows that the distributions of HDIs over 19904242000 (calibration and validation periods) include almost every observed as well as modeled 
425 HDIs from the calibration/validation dataset. In fact, for the SC season (see Figure 4a and 426 Figure $4 b$ ), only the observed ${ }_{7 d} Q_{\min }$ for 1996 is not included in the computed distribution. For 427 the SF season, three ${ }_{7 d} Q_{\min }$ are not included in the distribution (1991, 1996 and 1999) while 428 all observed ${ }_{30 d} Q_{\min }$ are included in the computed distribution.

429 Because the past temporal horizon (1971-2000) does not cover the calibration/validation 430 period (2000-2010) for the Yamaska watershed, Figure 5 only shows the distributions of the 431 HDIs computed from the 10 climate simulations supplied by Ouranos (available between 432 1961-2100). For the SC season, except for the $2006{ }_{7 d} Q_{\min }$, the computed distributions cover 433 the observed values. Modeled ${ }_{7 d} Q_{\min }$ for 2001 , and ${ }_{30 d} Q_{\min }$ for $2001,2002,2004$, and 2006, 434 are not included in the computed distributions. For the SF season, $50 \%$ of the observed HDIs 435 are not included in the computed distributions while $27(3 / 11)$ and $36 \%(4 / 11)$ of the modeled

436 HDIs are not included in the distributions for the $7 d$ - and ${ }_{30 d} Q_{\min }$, respectively.

437 Figure 4: Boxplots of the HDls computed from the modeling of the 42 climate scenarios for the Bécancour 438 watershed: (a) SC season ${ }_{7 d} Q_{\min }$; (b) $S C$ season ${ }_{30 d} Q_{\min }$; (c) $S F$ season $7 d Q_{\min }$; and (d) $S F$ season ${ }_{30 d} Q_{\text {min. }}$. Blue and red dots stand for the HDls computed during the calibration/validation process from the observed and modeled flows, respectively.

Figure 5: Boxplots of the HDls computed from the modeling of the 10 Ouranos climate scenarios for the Yamaska watershed: (a) SC season ${ }_{7 d} Q_{\min }$; (b) $S C$ season ${ }_{30 d} Q_{\min }$; (c) $S F$ season ${ }_{7 d} Q \mathrm{Qmin}$; and (d) $\mathrm{SF}$ season ${ }_{30 \mathrm{~d}} \mathbf{Q}_{\min }$. Blue and red dots stand for the HDls computed during the calibration/validation process from the observed and modeled flows, respectively. 


\section{$447 \quad 3.2$ Assessing HDls from CDls}

448 This subsection introduces the characterization of the statistical relationships between HDIs 449 and CDIs. First, it consists in assessing the strength and significance of the relationships 450 (through correlation coefficients and $95 \% \mathrm{Cl}$ ), their linear or non-linear character, and their 451 consistency over temporal horizons (Past and Future) and locations (Bécancour and 452 Yamaska). Then, it is about verifying whether the identified CDIs governing low flows: (i) 453 complied with the hypotheses made in the methodological framework and (ii) provided 454 insights about the HDls.

455

456

457

458

459

460 461

462

463

464

465

466

\subsubsection{Performances of the CDI groups}

The previous subsection established that the modeling of the 42 scenarios for the past temporal horizon effectively, and in a satisfactory manner pending some assumptions, represented low flow HDIs for the Bécancour and Yamaska watersheds, respectively. Thus as illustrated in Figure 1 and in the Materials and Methods section, CDls were computed over one to six days, one to three weeks, one to six months, eight, ten and twelve months. Figure 6 introduces the performances of the CDI groups with respect to the four categories introduced in Table 1. Results are displayed using the median of the Pearson correlation coefficients $r$ between the HDIs and the CDIs. Meanwhile, the specific CDIs having the better correlations with the HDls are reported in subsection 3.2.2. A Monte Carlo resampling approach was applied to compute the $95 \%$ Cls of each correlation coefficient. A Wilcoxon rank-sum test was applied to test whether median correlations were different between past and future temporal horizons. Results are presented for the Bécancour watershed only because those of the Yamaska are similar (detailed results for both watersheds available in supporting materials 3 and 4 ). 
Figure 6: Pearson median correlations $\mathrm{r}$ [95\% confidence interval $\mathrm{Cl}$ ] for the Bécancour watershed, for the SC (blue) and SF (green) seasons, for the ${ }_{7 d} Q_{\min }$ (solid triangles) and ${ }_{30 \mathrm{~d}} \mathbf{Q}_{\min }$ (hollow triangles), and for the past (left side) and future (right side) temporal horizons. The $95 \% \mathrm{Cl}$ was computed through Monte Carlo resampling of the 42 climate scenarios. The red dotted line stands for Wilcoxon tests that rejected the null hypothesis (median correlations are equal between past and future horizons) at the $5 \%$ significance level.

Past horizon

477 The median correlations obtained for the precipitation data CDls for the 42 scenarios over 478 the past temporal horizon for the SC season are at least 0.62 ; meaning that $38 \%$ of the 479 variability of low flows is explained through a basic CDI, namely cumulative rainfall over six or three months for the ${ }_{7 d} Q_{\min }$ and ${ }_{30 d} Q_{\min }$, respectively. For the SF season, the correlations are similar and explain at least $31 \%\left(0.56^{2}\right)$ of the variability; these are obtained for the cumulative rainfall over two months. The literature (Yang et al., 2002; Hodgkins et al., 2005; de Wit et al., 2007; Novotny and Stefan, 2007; Ge et al., 2012) reported linear correlation coefficients around 0.7 which coincides with the $8^{\text {th }}$ or $9^{\text {th }}$ decile (available in supporting material 3) of the computed coefficients for both the Bécancour and Yamaska watersheds.

The median correlations obtained for temperature data CDIs are much lower and, thus, less interesting within the framework of this paper. The explained variability ranges from 15 $\left(0.39^{2}\right)$ to $22 \%\left(0.47^{2}\right)$. These figures as well as the negative and positive correlations reported for warmer and colder months respectively are in agreement with the literature (Yang et al., 2002; Hodgkins et al., 2005; de Wit et al., 2007; Ge et al., 2012).

491 The median correlations obtained for blended data as well as drought indices are higher than 492 those obtained for either precipitation or temperature data. They explain at least $49 \%\left(0.70^{2}\right)$ 493 of the variability. The classical SPI and PDSI indices, as well as the EDI were all part of the 494 drought indices group (Table 1). In theory, the three indices were comparable; they could all 495 be used to detect dry spells as well as wet spells, like all the CDIs introduced in Table 2. In 496 practice, the EDI has been found to perform systematically (for all scenarios) better than the 497 other indices. In fact, results (not shown) showed that the PDSI, the SPI as well as the Zscore did not perform better (correlation difference not statistically significant) than the basic 
499 CDIs (computed from either precipitation or temperature data). In terms of linear correlation 500 with the HDls, they did not provide added value.

501 The $95 \%$ Cls (see Figure 6) demonstrate that all Pearson median correlation coefficients 502 were significant and not obtained by chance. Indeed these ranges for the true values of the

503 correlations were computed from 1000 resampling of the HDI-CDI couples for every 504 scenarios. The lower bound indicates the lowest possible median correlation given a $5 \%$ 505 chance of error. For the blended and drought indices data, these lower bounds are all greater 506 or equal to 0.66 .

507 In addition to this linear method, the non-linear method based on the computation of 508 Spearman median correlations rho was also used, but because median correlations of both 509 types were systematically similar, it is not presented here (results available in supporting 510 material 3). In itself, this result indicates that the HDI-CDI-relationship is mostly linear, which 511 corroborates findings reported by Assani et al. (2011) who also considered this alternative. Future horizon

513 Results for the future horizon introduced in Figure 6 illustrate, for the same CDIs used in the 514 past temporal horizon, the median correlations obtained for the 42 scenarios. Median 515 correlations for the precipitation and temperature data CDIs remain of the same order of 516 magnitude, but the $95 \%$ Cls get mostly larger. The Wilcoxon tests were unable to reject the 517 null hypothesis that median correlations are equal between past and future horizons for all 518 CDI-HDI couples besides the SC season precipitation data CDIs.

519 Blended data and drought indices median correlations remained approximately the same 520 between past and future horizons (mean difference under 5\%). Except for the SC season 521 blended data ${ }_{7 d} \mathrm{Q}_{\min } \mathrm{CDI}$, the Wilcoxon tests were unable to reject the hypothesis that median 522 correlations are equal between past and future horizons. 95\% Cls also got larger (decrease 523 of the lower bound). Overall, not accounting for the CDI that passed the Wilcoxon test, 524 median correlations still explained between $46\left(0.68^{2}\right)$ and $59 \%\left(0.77^{2}\right)$ of the variability in the future temporal horizon. This result is quite important because, it confirms that the linear 
526 relationship detected between $\mathrm{CDI}$ and HDI for the past remains valid in the future, thus it 527 can be used to gain insights on the CDI governing low flows in the future. Furthermore, to the 528 authors' knowledge, no study has carried out correlation analyses from past horizons to 529 future horizons using climate scenarios.

530 For the remaining of the article, because of their superior performances (larger median 531 correlations and/or narrower $95 \mathrm{Cls}$ ), results are limited to the CDIs computed from blended 532 data and drought indices. For this specific case study, they are more appropriate to work with 533 than the two other CDI groups. Also, the CDIs that passed the Wilcoxon test are not used to 534 get insights about the future HDIs as they did not verify one of the methodological framework 535 hypotheses.

$536 \quad 3.2 .2$ CDI governing low flows

537 Table 5 introduces the results obtained after application of the methodological framework 538 introduced in Figure 1. The Bécancour watershed was first considered as the reference and 539 the CDIs are exported onto the Yamaska watershed for a spatial validation and vice versa. 

of the methodological framework using (a) Bécancour as the reference watershed and then (b) Yamaska as the reference watershed

\begin{tabular}{|c|c|c|c|c|c|}
\hline & \multirow[t]{2}{*}{ (a) } & \multicolumn{2}{|c|}{ Bécancour (Reference) } & \multicolumn{2}{|c|}{ Yamaska (Spatial Validation) } \\
\hline & & $S C$ & $S F$ & SC & $S F$ \\
\hline \multirow{2}{*}{${ }_{7 d} Q_{\min }$} & Blended data & N.A. & $0.74 / 0.74$ & N.A. & $0.70 / 0.67$ \\
\hline & Drought Indices & $0.74 / 0.68$ & $0.78 / 0.75$ & $0.76 / 0.72$ & $0.73 / 0.70$ \\
\hline \multirow{2}{*}{${ }_{30 d} Q_{\min }$} & Blended data & $0.72 / 0.77$ & $0.73 / 0.75$ & $0.71 / 0.70$ & $0.67 / 0.68$ \\
\hline & Drought Indices & $0.70 / 0.69$ & $0.75 / 0.74$ & $0.68 / 0.74$ & $0.75 / 0.73$ \\
\hline & (b) & \multicolumn{2}{|c|}{ Bécancour (Spatial Validation) } & \multicolumn{2}{|c|}{ Yamaska (Reference) } \\
\hline \multirow{2}{*}{${ }_{7 d} Q_{\min }$} & Blended data & $0.69 / 0.68$ & $0.73 / 0.69$ & $0.69 / 0.63$ & $0.70 / 0.65$ \\
\hline & Drought Indices & $0.74 / 0.71$ & $0.78 / 0.75$ & $0.76 / 0.74$ & $0.73 / 0.70$ \\
\hline \multirow{2}{*}{${ }_{30 d} Q_{\min }$} & Blended data & $0.65 / 0.77$ & $0.70 / 0.62$ & $0.73 / 0.75$ & $0.76 / 0.77$ \\
\hline & Drought Indices & N.A. & $0.75 / 0.74$ & N.A. & $0.75 / 0.73$ \\
\hline
\end{tabular}

543

544

545

546

547

N.A. stands for CDI-HDI couples that passed the Wilcoxon rank-sum test and thus did not respect the hypothesis according to which median correlations should remain the same between past and future horizons

Overall, when Bécancour was the reference watershed, the explained variability $\left(r^{2}\right)$ for the Yamaska watershed was greater than $45 \%\left(0.67^{2}\right)$ for the ${ }_{7 d} Q_{\min }$ and the ${ }_{30 d} Q_{\min }$ for both temporal horizons. When Yamaska was used as the reference watershed, the explained variability for Bécancour past horizon varied between $42\left(0.65^{2}\right)$ and $61 \%\left(0.78^{2}\right)$. Meanwhile for the future horizon, it varied between $38\left(0.62^{2}\right)$ and $59 \%\left(0.76^{2}\right)$. The differences between parts (a) and (b) of Table 5, where the watersheds were in turn used for calibration or spatial validation, are not statistically significant, except for the SF season ${ }_{30 d} Q_{\min }$ blended data CDI for both temporal horizon and the future only respectively for the Yamaska and Bécancour watersheds, according the Wilcoxon rank-sum test at $5 \%$ significance level. This means that it cannot be asserted that performances are significantly different for the same watershed, whether it is used as the reference or export watershed. This result can hardly be seen as a proof that the statistical relationship captured on a watershed is applicable to another, but it provides a good insight as for the potential of this method for regionalization studies.

Moreover, the differences in performances might be larger if the considered watersheds were in different geological areas or further away from each other physiographically speaking. 
561 These two points would mandate for the application of the methodological framework on 562 other watersheds to assess the robustness with regards to physiographical differences. 563 However, in terms of hydrologic model performance rating (Moriasi et al., 2007), the median 564 Pearson correlation coefficients were considered "acceptable" since they were all greater 565 than 0.5 (Santhi et al., 2001; Van Liew et al., 2003), even for the great majority of $1^{\text {st }}$ deciles.

566 As anticipated, the results are quite similar for the two studied watersheds. Indeed, the study 567 focused on identifying the main governing indices of low flows while building on the 568 assumption that physical links between HDIs and CDIs remained time invariant (between 569 past and future horizons). As such, this approach may be viewed as the temporal equivalent 570 of the global calibration strategy of distributed hydrological models (Ricard et al., 2013). It 571 was notably used in $C E H Q(2013 b, 2015)$ to ensure the spatial consistency of the calibration 572 parameter sets in large-scale hydrological modeling applications. Meanwhile the choice to 573 work with best median correlations for each type of input data in this paper ensured that the 574 identified CDIs in subsection 3.2.2 were valid for each of the 42 climate scenarios.

575 Following the methodological framework introduced in Figure 1, the CDIs from the blended data and drought indices groups that are better correlated with the HDIs (Figure 6) are 577 identified hereafter. For both study watersheds, the severity of 7-day low flows of the SC 578 season was best correlated with the EDI computed from rainfall and snowmelt minus PET 579 amounts over 10 months. SC season 30-day low flows were best correlated with the same 580 index, but over the course of 10 and 12 months for the Yamaska and Bécancour watershed, 581 respectively. The latter result is rather logical, given that 30-day-low flows can mobilize more 582 water reserves than 7-day-low flows. It is noteworthy that the accumulation of rainfall and melt over three months and rainfall plus melt minus PET over two months are also correlated 584 with the 30-day low flows of the Bécancour and Yamaska watersheds, respectfully. This 585 would highlight the importance of working at different time scales as CDls computed from 586 blended data seem best correlated at lower frequencies than drought indices CDIs. Indeed, 587 the same observation can be made for the CDls computed for the SF season. 
SF season 7- and 30-day-low flows were correlated with cumulative climatic demand over

589 four to six months, indicating that lower rainfall amounts or higher PET amounts would 590 translate into lower low flows. The specific case of the inclusion of melt in the CDI computed 591 for the Yamaska watershed for the SF season ${ }_{30 d} Q_{\min }$ may be startling. But in fact, this result 592 is linked with the depletion of groundwater storage. Accumulation of rainfall over a month is 593 the primary CDI driver (for precipitation data CDI) of ${ }_{30 d} \mathrm{Q}_{\min }$ with a median correlation of 0.72 594 (shown in supporting material 4 ) and $1^{\text {st }}$ and $9^{\text {th }}$ deciles of 0.35 and 0.83 . Accumulation of 595 rainfall and snowmelt over a month is the primary CDI driver (for blended data) of ${ }_{30 d} Q_{\min }$ with 596 a median correlation of 0.76 ((b) Table 5) and $1^{\text {st }}$ and $9^{\text {th }}$ deciles of 0.52 and 0.84 . The 597 difference in median correlations is not significant, but the difference in the $1^{\text {st }}$ deciles is. This 598 could be interpreted as follows: When melt occurs shortly (less than a month) before the date 599 of occurrence of the ${ }_{30 d} \mathrm{Q}_{\min }$, the stored amount of snowmelt helps relieve the severity of low 600 flows, but this happened rarely over the 42 scenarios ( $1^{\text {st }}$ decile difference). Another 601 explanation could be that man-made reservoirs are mainly filled thanks to snowmelt. Last but 602 not least, this result could not be random for two reasons: (i) this phenomenological 603 observation, however less important, manifested also for the Bécancour watershed ((b) 604 Table 5), the correlations for ${ }_{30 \mathrm{~d}} \mathrm{Q}_{\min }$ blended data are 0.70 and 0.62 for the past and future 605 horizons); and (ii) the $95 \% \mathrm{Cl}$ for the true value of the median correlation coefficient for the 606 Yamaska watershed is [0.72 - 0.81] (supplemental material 4).

607 Otherwise, SF season 7- and 30-day-low flows were best correlated with EDI computed from 608 climatic demand over 6 months for both watersheds.

609

610

611 Trend analyses of the HDI and associated CDI series were undertaken to check for long term 612 changes, thanks to the modified MK test (Hamed and RamachandraRao, 1998). Field 613 significance was assessed, applying a bootstrap resampling method based on Monte Carlo 614 simulations. Both local significance and field significance were set at $1 \%$. An overview of the 
615 results for the ten continuous scenarios is given in Table 6. Indeed, data from the 32 non616 continuous scenarios came in two 29-year temporal horizons, which in most cases prevented

617 the detection of positive or negative trends altogether

618 Table 6 : Trends detected in the HDI and CDI series for the (a) Bécancour and (b) Yamaska watersheds for 619 the 10 scenarios by Ouranos over 1971-2070. CDI1 stands for the CDI computed from blended data, while 620 CDI2 stands for CDI computed from drought indices. Bold figures indicate significant trends.

(a) Bécancour

\begin{tabular}{|c|c|c|c|c|}
\hline & \multicolumn{2}{|c|}{ Snow Cover Season } & \multicolumn{2}{|c|}{ Snow Free Season } \\
\hline & HDI - CDI1 - CDI2 & $\mathrm{HDI}-{ }_{\mathrm{CD}}{ }_{\mathrm{CD}} \mathrm{Q}_{\min }-\mathrm{CDI} 2$ & $\mathrm{HDI}-{ }_{\mathrm{7d}} \mathrm{Q}_{\min }$ & $\mathrm{HDI}-{ }_{\mathrm{C}}^{30 \mathrm{~d}} \mathrm{Q}_{\min } 1-\mathrm{CDI} 2$ \\
\hline Positive trends & $10-$ N.A. -10 & $10-10-10$ & & \\
\hline Negative trends & & & $8-8-$ N.A. & $8-8-8$ \\
\hline $\begin{array}{l}\text { Significant } \\
\text { trends (positive } \\
\text { \& negative) }\end{array}$ & $10-$ N.A. -10 & $10-10-10$ & $8-8-N . A$. & $8-8-8$ \\
\hline
\end{tabular}

(b) Yamaska

Snow Cover Season

Snow Free Season

Positive trends

\begin{tabular}{cccc}
\hline $\mathrm{HDI}-\mathrm{CDI} 1-\mathrm{CDI} 2$ & $\mathrm{HDI}-{ }_{\mathrm{C}} \mathrm{CDI}_{\min } \mathrm{Q}_{\min }-\mathrm{CDI} 2$ & $\mathrm{HDI}-{ }_{\mathrm{Cd}} \mathrm{CDI}_{\min }-\mathrm{CDI} 2$ & $\mathrm{HDI}-{ }^{30 \mathrm{~d}} \mathrm{Q}_{\min }$ \\
\hline $9-\mathrm{N} . \mathrm{A} .-10$ & $10-10-10$ & $0-1-0$
\end{tabular}

Negative trends

$7-8-10$

$7-2-9$

Significant trends (positive

$9-$ N.A. -10

$10-10-10$

$7-8-10$

7-3-9

\& negative) 
Table 7 : Pearson median partial correlation coefficients $r$ (Past horizon/Future Horizon/1971-2070) for the Bécancour and Yamaska watersheds for the CDIs obtained after application of the methodological framework for the 10 scenarios by Ouranos. CDI1 stands for the CDI computed from blended data, while CDI2 stands for CDI computed from drought indices.

(a) Bécancour Watershed

\begin{tabular}{ccccc} 
& \multicolumn{2}{c}{ SC season } & \multicolumn{2}{c}{ SF season } \\
\cline { 2 - 5 } & CDI1 & CDI2 & CDI1 & CDI2 \\
\cline { 2 - 3 }${ }_{7 d} Q_{\min }$ & N.A. & $0.74 / 0.65 / 0.68$ & $0.71 / 0.61 / 0.68$ & N.A. \\
${ }_{30 d} Q_{\min }$ & $0.77 / 0.75 / 0.73$ & $0.69 / 0.62 / 0.64$ & $0.70 / 0.73 / 0.70$ & $0.66 / 0.66 / 0.66$ \\
\hline
\end{tabular}

a

\begin{tabular}{ccc:cc} 
& CDI1 & CDI2 & CDI1 & CDI2 \\
\cline { 2 - 5 }${ }_{7 d} Q_{\min }$ & N.A. & $0.78 / 0.71 / 0.74$ & $0.73 / 0.71 / 0.66$ & $0.62 / 0.63 / 0.58$ \\
${ }_{30 d} Q_{\min }$ & $0.74 / 0.78 / 0.73$ & $0.73 / 0.75 / 0.72$ & $0.73 / 0.72 / 0.63$ & $0.71 / 0.63 / 0.61$ \\
\hline
\end{tabular}

All partial correlation coefficients are significant at 0.001 .

Both Bécancour and Yamaska $S C{ }_{7 d} Q_{\min }$ as well as ${ }_{30 d} Q_{\min }$ have increasing linear significant trends (Table 6) as indicated by CEHQ (2015) for most of southern Québec with a high confidence level. These trends are probably linked to an increase in freeze/thaw events or warm events during the SC season (included in supporting material 2) and as a direct consequence, modified snowmelt dynamics. The associated CDIs, whether computed from blended data or drought indices, also displayed these increasing trends (Table 6). They were in almost perfect agreement with the HDI trends. Meanwhile, the partial correlations removing the temporal trends were not only significant (Table 7 and $95 \% \mathrm{Cl}$ available in supporting materials 3 and 4), but quite high as well. Indeed, the CDIs explained more than $48\left(0.69^{2}\right)$ and $38 \%\left(0.62^{2}\right)$ of the HDI variability for the Bécancour watershed over the past and future temporal horizons, respectively. Values were even larger for the Yamaska watershed with at least $53\left(0.73^{2}\right)$ and $50 \%\left(0.71^{2}\right)$ of the HDI variability explained for the past and future horizons, respectively. Overall, compared to median Pearson correlations for the same CDIs and the 10 continuous scenarios, median partial correlations (supporting 
641 material 5) were only $3.2 \%$ smaller on average with a maximum difference of $6.8 \%$ for the

642 SC season Bécancour CDIs. These partial correlations values are large, the lower bound of 643 the $95 \% \mathrm{Cl}$ (supporting materials 3 and 4) is still considered "acceptable" (larger than 0.5 644 (Santhi et al., 2001; Van Liew et al., 2003)) in terms of hydrologic performance rating 645 (Moriasi et al., 2007), and the associated trends in the CDls were in almost perfect 646 agreement with the HDI trends (Table 6). Given these results, it is then possible to attribute 647 the observed trends in SC low flows to trends in the CDIs identified in subsection 3.2.2 for 80 648 to $100 \%$ of the climate scenarios.

649 The same reasoning can be made about the SF season low flows. 70 and $80 \%$ of the 650 decreasing trends in HDIs were significant and concurred with results reported in $C E H Q$ 651 (2015) for southern Québec. The associated CDIs had matching trends (except for the CDI 652 computed using blended data for the Yamaska ${ }_{30 d} Q_{\min }$ in Table 6), while the partial 653 correlations between the HDIs and CDIs were high (above 0.62 for the past temporal horizon 654 and above 0.61 for the future temporal horizon) and the lower bounds of their $95 \% \mathrm{Cl}$ 655 remained "acceptable". Given these results, it is then possible to attribute the observed 656 trends in SF low flows to trends in the CDIs identified in subsection 3.2 .2 for 70 to $100 \%$ of 657 the climate scenarios.

658 4. Discussion

659 The following section deals with the relevance of the main assumptions made throughout the 660 paper, more specifically it: (i) shows how sources of climate uncertainty were considered 661 while selecting the climate simulations and emissions scenarios; (ii) examines the validity of 662 the assumptions regarding the stationarity of climate conditions, land use, and land cover; 663 (iii) details how HDIs and (iv) CDIs actually captured what is observed; (v) discusses the 664 robustness of the results; and (vi) argues the proposed methodology has potential to be 665 applicable to watersheds with regulated flows. 


\subsection{Choice of climate simulations}

667 It has been established since the Fourth Assessment Report of the Intergovernmental Panel 668 on Climate Change (Meehl et al., 2007b) that using a multi-model ensemble approach 669 provides better estimates of climate on seasonal-to-interannual and centennial time scales 670 (Palmer et al., 2004; Hagedorn et al., 2005). In this paper, the climate ensemble (cQ)² was 671 used. It was put together while taking into account the individual performances as well as the 672 independencies of the models. The climate ensemble was built to cover all sources of 673 climate uncertainty (Hawkins and Sutton, 2011), but the emissions scenarios. Natural climate 674 variability was covered through the use of different initial conditions (members) for the same 675 GCM. Different GCMs were used to drive the same RCM to account for the uncertainty 676 arising from the climate modeling. GCMs and RCMs were used together in the same 677 ensemble to account for the uncertainty arising from the spatial resolution of data (dynamical 678 downscaling). Lastly, the premise to work with only the SRES-A2 scenario was based on the 679 following elements: (i) emissions scenarios other than SRES-A2 are non-essential to cover 680 the uncertainty of the climate change signal (see supporting material 2) and (ii) small or even 681 negligible uncertainty arises from emissions scenarios for all regions and lead time within the 682 CMIP3 multi-model ensemble (Hawkins and Sutton, 2011). However, simulations of a multimodel ensemble cannot span the full range of possible model configurations due to 684 constraints in resources (Lambert and Boer, 2001). Furthermore, the use of ensemble 685 means/medians can mask the variations between models (Kingston et al., 2011). Indeed, 686 projections of future precipitation often disagree, even in the direction of change (Randall et 687 al., 2007). That is why, this paper considered the model ensemble resorting to median to 688 summarize the results, but providing the distribution or the $1^{\text {st }}$ and $9^{\text {th }}$ deciles to avoid 689 masking model differences. In a future implementation of the methodology, the different sources of uncertainty could be assessed. 


\subsection{Non stationarity issue}

692

693

694

695

696

697

698

699

700

701

702

703

704

705

706

707

708

709

710

711

712

713

714

715

716

717

\subsubsection{Calibration/validation}

Non-stationarity is an inherent issue of the calibration/validation process for hydroclimate studies. In this paper, meteorological data were the only varying characteristic of the modeling set up. We assumed that non-stationarity should not impact the values of the model parameters considering that: (i) only one calibrated parameter - related to evapotranspiration - was linked to variation in meteorological data and (ii) relatively similar ranges of mean annual/seasonal temperature and precipitation were found for both the calibration/validation period and the future period (see supporting material 2).

\subsubsection{CDI/ HDI statistical relationship}

The stationarity assumption made with respect to climate conditions, applied to the link between CDIs and HDIs, was tested in subsection 3.2. Overall, $3 / 4$ of the Wilcoxon rank-sum tests failed to reject the hypothesis that median correlations were equal between past and future horizons at the $5 \%$ significance level (Figure 6). That is why it was assumed that the stationarity assumption was valid with respect to the captured statistical links. Nonetheless, it could prove useful in a future paper to challenge this assumption by allowing the frequency at which CDIs are computed for the past horizon to change. This would allow assessing the effect of climate change on lags between the occurrence of the HDIs and the building of the CDIs.

In this study, it was assumed that land use and land cover would remain stationary in the future. The exact influence of any changes in these watershed attributes, however, could be accounted for by defining future land cover scenarios, but this was beyond the scope of the paper. Nonetheless, as showed by Savary et al. (2009), significant changes in land use and/or land cover can occur over a long period (e.g., 30 years) and, as illustrated using distributed hydrological modelling, modify stream flows. However, these changes would not nullify the intrinsic relationships between flows and weather data. Indeed, the evaluation of the impact of land use and land cover modifications performed by Savary et al. (2009) was 
718 carried out with the same sets of parameter values without impeding the calibration results.

719 This is definitely an argument to be made in favor of asserting that land cover and land use

720 modifications would not dramatically change the developed CDI - HDI correlations.

721

722

\subsubsection{Post-processing of climate data}

As for the post-processing method, a change factor approach could have also been used. It consists in computing the difference between raw climate model outputs for the future and reference periods, resulting in "climate anomalies" which are then added to the present day observational dataset (Wilby et al., 2004; Karyn and Williams, 2010).

\subsection{Computation of the HDls}

The goal of this paper is not to predict seasonal HDIs accurately but rather to establish whether it is possible or not to evaluate their trends and governing CDIs computed using climate data. The observed HDIs are properly captured for the Bécancour watershed (Figure 4), but less so for the Yamaska watershed (Figure $5 c$ and d). Indeed, for the SF season, the observed HDls are greater than the modeled HDIs. This may be attributed in part to the presence of small man-made reservoirs used for water supply. Indeed, these were not explicitly modeled by HYDROTEL, although they are currently used to support low flows (especially the Choinière Reservoir, see Figure 3b) which would explain that observed low flows are larger than those modeled. Moreover, this would explain the better agreement between observed and modeled HDls over the SC season when the reservoirs are not used to either support low flows or mitigate floods. The underlying assumption is that this supporting/mitigating function does neither alter the CDIs governing low flows, nor modify the trends of HDIs. This assumption is validated by the results obtained when exporting the CDIs identified for the Bécancour watershed to the Yamaka watershed (Table 5).

\subsection{CDI driving low flows}

The CDIs identified as the drivers of low flows (see subsection 3.2.2) concurred with those reported in the literature (Table 2) and deemed responsible for low flow generating 
744 processes (Waylen and Woo, 1987; Sushama et al., 2006). Low flows generally result from: 745 (i) storage depletion (following below freezing temperatures) in winter and (ii) lack of 746 precipitation and increased evapotranspiration during summer. As for the associations 747 between CDIs and HDIs, it should be kept in mind that association does not always imply 748 causation. Although the discussion of this issue is beyond the scope of this paper, the reader 749 is referred to Hill (1965) who proposes a series of questions to differentiate association and 750 causation:

751 752 753 754 755 756 757 758 759 760

- Strength: Is the correlation between HDIs and CDIs identified in subsection 3.2 sufficiently stronger than the correlation between HDIs and any CDI taken from the literature?

- Specificity: Is the association with HDIs limited to a few specific CDIs?

- Consistency: Has the association been repeatedly observed in different places, circumstances and times?

- Plausibility and coherence: Was the association hydrologically plausible? Did the cause and effect interpretation of the data conflict with the generally known facts of low flow hydrology (coherence)?

\subsection{Trend detection}

The detected trends in SF and SC low flows were attributed to the corresponding trends in CDIs through partial correlation analysis and modified MK test. These trends appeared more often that one could expect from chance alone. Assessing the trends and their attribution for the 42 scenarios, instead of the 10 supplied by Ouranos, would improve the confidence in the stated results. Indeed, the $10 \mathrm{CRCM}$ simulations used two GCMs only (Table 1) and are not enough to establish any measure of climate uncertainty. But they are enough to get a first idea about the variability of the direction of changes considering the meteorological variations they propose. Indeed, they were deemed representative of a myriad of potential climate changes using the cluster method (Hartigan and Wong, 1979). Plus, the two selected GCMs are very well rated (Gleckler et al., 2008) when compared to models of the CMIP3 ensemble. 
771 These GCM-RCM combinations are commonly used (Grillakis et al., 2011; Rousseau et al., 772 2014; Fossey and Rousseau, 2016b; Klein et al., 2016) and were therefore deemed suitable 773 for this study.

774 Velázquez et al. (2013) showed that the choice of a hydrological model can affect the 775 detected changes from past to future horizons, especially for low flow indices. But they did 776 not work with trends at all. Nonetheless, for a more comprehensive study it would be useful 777 to use different hydrological models to compute the studied HDIs and their matching CDIs. 778 Despite these shortcomings in trend detection, the attribution of trends in HDls to trends in 779 CDIs is rather important, as it illustrates the potential of using solely the more recent climate 780 continuous simulations of CMIP5 (Guay et al., 2015) to assess HDI trends.

781

782

783

784 785 786 787

\subsection{Regulated flows of the Yamaska watershed}

The flows of the Yamaska watershed are partly regulated. Stations 030302, 030304 and 030345 (see Figure 3b) respectively measure monthly and daily regulated flows (CEHQ, 2017). These regulations are of different kinds. Over the watershed, there are 149 dams of more than one meter in height (COGEBY, 2010). But the only one that has more than a local effect on flows (COGEBY, 2010) is the Choinière reservoir (Figure 3b). Some dams are used for irrigation purposes while others receive water from agricultural drainage systems. Côté et al. (2013) developed a low flow warning system prototype for the Yamaska watershed. They decided to model the watershed with HYDROTEL while removing the effect of the Choinière reservoir (by setting the outflows) to model natural flows (at least with respect to the flow regulation from this dam). This resulted in calibration and validation results not exceeding NSE values of 0.46 and 0.53 at river segment TR-61 (Figure 3b), respectively. These results are clearly not as good as those obtained in Table 4. Plus, the results obtained in this paper for the Yamaska watershed are comparable to those of the Bécancour watershed, suggesting that flow regulation may be limited or at least that the calibration was able to account for it. On top of that, the issue of regulated flow is one that needs addressing. Over the 9000 USGS hydrometric stations, more than $3 / 4$ are at least partly regulated (Falcone, 
2011). For these reasons, the Yamaska watershed was modeled without removing the effect of the Choinière reservoir, with only the meteorological data input varying from past to future 800 horizon.

801 Results with respect to the Yamaska watershed throughout this paper are comparable to 802 those obtained for the unregulated flows of the Bécancour watershed. Pearson median 803 correlations (Figure 6) were of similar for all types of CDIs, the CDls identified as governing 804 low flows were almost identical between watersheds, even the trend detection and attribution 805 analyses (Table 6 and Table 7) gave really similar results. Overall, this paper shows that the 806 statistical framework introduced in this paper has potential to be applicable to watersheds 807 with regulated flows. This topic of course needs in-depth research and will be further 808 reinforced in a future paper dealing with more watersheds from different hydrological regions 809 of Québec including a distinct paring process, clustering watersheds according to their 810 physiographic descriptors.

\section{5. Conclusion}

812 This paper introduced the development of a statistical framework to assess future trends and 813 forcing phenomena associated with low flows at the watershed scale using solely climate 814 data. From 22 CDIs, reported in the literature, a list of CDI-HDI couples was produced 815 according to their relationship captured through Pearson linear correlation coefficients for 42 climate scenarios (post processed simulations) under the greenhouse gas emissions

\section{7 scenario SRES-A2.}

818 For the hydrological SC season of the Bécancour watershed, the ${ }_{7 d} Q_{\min }$ and ${ }_{30 d} Q_{\min }$ were 819 paired with the EDI computed from rainfall plus snowmelt minus PET amounts over ten 820 months and the cumulative rain and snowmelt over three months, respectively. These CDIs explained $55 / 46 \%\left(r=0.74^{2} ; r=0.68^{2}\right)$ and $53 / 58 \%$ of the ${ }_{7 d} Q_{\min }$ and ${ }_{30 d} Q_{\min }$ over the past/future temporal horizons, respectively. For the SF season, the ${ }_{7 \mathrm{~d}} Q_{\min }$ and ${ }_{30 \mathrm{~d}} Q_{\min }$ were paired with

823 the cumulative difference between rainfall and PET over five months and the EDI computed 
824 from the latter difference over eight months, respectively. These couples had median 825 correlations of $0.74 / 0.73$ and $0.77 / 0.74$. These results correspond to the median 826 performances obtained when applying the methodology to 42 climate scenarios of the (cQ) ${ }^{2}$ 827 project (Guay et al., 2015). The statistical relationships remained valid for the future horizon 828 (no difference between median correlations of past and future temporal horizons according to 829 a Wilcoxon test), statistically significant and not due to chance (the lower bound of the 95\% $830 \mathrm{Cl}$ for each median correlation coefficient remained at least above 0.6), and were applicable 831 to the second study watershed with no significant loss in performance.

832 Furthermore, significant trends between 1971 and 2070 in the HDIs extracted from 10 833 scenarios supplied by Ouranos were attributed to trends in the matching CDIs. This finding 834 was assessed using linear trend and partial correlation analyses. For both watersheds, 835 observed trends in SC and SF low flows were attributed to trends in the aforementioned 836 CDIs for 80 to $100 \%$ and 70 to $100 \%$ of the climate scenarios, respectively. SF season 837 trends indicated a downward tendency, while SC season trends indicated an upward 838 tendency. These four assessed trends agreed with the results presented by CEHQ (2015) 839 who did use a hydroclimatological modeling framework. This is rather important as it 840 demonstrates the ability of the proposed framework to indicate whether or not a HDI will 841 increase or decrease without requiring the use of a hydrological model.

842 The developed methodology can be adapted easily. Indeed, in this paper, we worked with 22 843 CDIs; chosen because of their known relationships with low flows. Working with other HDIs 844 or in another field of study could entail working with other indices. The methodology was 845 designed with the intent of accounting for recent advances in climate research and could be 846 further corroborated using the CMIP5 simulations (PCMDI, 2016); carrying out the same 847 framework and obtaining a score based on a larger number of continuous scenarios. 848 Furthermore, application of the proposed methodology would lead to a screening 849 assessment of future drought-prone-watersheds; that is those that could benefit from an in850 depth hydroclimatic modeling study. 
851 Overall, this paper contributes to the advancement of knowledge in the climate phenomena 852 governing low flows. When compared to the conventional approach (i.e. combining climate 853 scenarios with hydrological models) widely used to assess future low flows at the watershed 854 scale, this paper, based on a limited case study with a single hydrological model, introduced 855 a relatively simple methodology to assess hydrological trends using solely climate data and 856 proposed, for a future temporal horizon, statistical relationships between CDIs and HDIs. 


\section{ACKNOWLEDGEMENTS}

859 The authors would like to thank Marco Braun and Diane Chaumont of Ouranos (Consortium

860 on Regional Climatology and Adaptation to Climate Change, Montreal, Qc, Canada), for their 861 scientific support, and Stéphane Savary and Sébastien Tremblay of INRS (Centre Eau Terre 862 Environnement) for their timely technical advices throughout the project. We also thank the 863 reviewers for their time, thorough revisions and helpful comments and suggestions. Financial 864 support for this project was provided by the Natural Sciences and Engineering Research 865 Council (NSERC) of Canada through their Discovery Grant Program (A.N. Rousseau, 866 principal investigator). 


\section{References}

869

870

871

872

873

874

875

876

877

878

879

880

881

882

883

884

885

886

887

888

889

890

891

892

893

894

895

896

897

898

899

900

901

902

903

904

905

906

Abdul Aziz, O. I., and D. H. Burn (2006), Trends and variability in the hydrological regime of the Mackenzie River Basin, Journal of Hydrology, 319(1-4), 282-294. doi: 10.1016/j.jhydrol.2005.06.039.

Akthari, R., S. Morid, M. H. Mahdian, and V. Smakhtin (2009), Assessment of areal interpolation methods for spatial analysis of SPI and EDI drought indices, International Journal of Climatology, 29, 135-145.

Assani, A. A., R. Landry, and M. Laurencelle (2012), Comparison of interannual variability modes and trends of seasonal precipitation and streamflow in southern Quebec (canada), River Research and Applications, 28(10), 1740-1752. doi: 10.1002/rra.1544.

Assani, A. A., A. Chalifour, G. Légaré, C. S. Manouane, and D. Leroux (2011), Temporal Regionalization of 7-Day Low Flows in the St. Lawrence Watershed in Quebec (Canada), Water Resources Management, 25(14), 3559-3574.

Beven, K. (2006), A manifesto for the equifinality thesis, Journal of Hydrology, 320(1-2), 1836. doi: 10.1016/j.jhydrol.2005.07.007.

Bouda, M., A. N. Rousseau, B. Konan, P. Gagnon, and S. J. Gumiere (2012), Case study: Bayesian uncertainty analysis of the distributed hydrological model HYDROTEL, Journal of Hydrologic Engineering, 17(9), 1021-1032. doi: 10.1061/(ASCE)HE.1943-5584.0000550.

Bouda, M., A. N. Rousseau, S. J. Gumiere, P. Gagnon, B. Konan, and R. Moussa (2014), Implementation of an automatic calibration procedure for HYDROTEL based on prior OAT sensitivity and complementary identifiability analysis, Hydrological Processes, 28(12), 39473961. doi: 10.1002/hyp.9882.

Burn, D. H. (2008), Climatic influences on streamflow timing in the headwaters of the Mackenzie River Basin, Journal of Hydrology, 352(1-2), 225-238. doi: 10.1016/j.jhydrol.2008.01.019.

Burn, D. H., and M. A. Hag Elnur (2002), Detection of hydrologic trends and variability, Journal of Hydrology, 255(1-4), 107-122. doi: 10.1016/S0022-1694(01)00514-5.

Burn, D. H., O. I. A. Aziz, and A. Pietroniro (2004a), A comparison of trends in hydrological variables for two watersheds in the Mackenzie River Basin, Canadian Water Resources Journal, 29(4), 283-298.

Burn, D. H., J. M. Cunderlik, and A. Pietroniro (2004b), Hydrological trends and variability in the Liard River basin, Hydrological Sciences Journal, 49(1), 53-68. doi: 10.1623/hysj.49.1.53.53994.

Byun, H. R., and D. A. Wilhite (1999), Objective quantification of drought severity and duration, Journal of Climate, 12(9), 2747-2756.

CEHQ. 2012. Niveau d'eau et débit. http://www.cehq.gouv.qc.ca/hydrometrie/index.htm (accessed September 2013).

CEHQ (2013a), Production de l'Atlas hydroclimatique du Québec méridional - Rapport technique, 31 pp, Centre d'expertise hydrique du Québec, Québec. 
CEHQ (2013b), Atlas hydroclimatique du Québec méridional - Impact des changements climatiques sur les régimes de crue, d'étiage et d'hydraulicité à l'horizon 2050, 21 pp, Québec.

CEHQ (2015), Hydroclimatic Atlas of Southern Québec. The Impact of Climate Change on High, Low and Mean Flow Regimes for the 2050 horizon, 81 pp, Québec.

CEHQ. 2017. Suivi hydrologique de différentes stations hydrométriques. https://www.cehq.gouv.qc.ca/suivihydro/default.asp (accessed 2017).

Choi, M., J. M. Jacobs, M. C. Anderson, and D. D. Bosch (2013), Evaluation of drought indices via remotely sensed data with hydrological variables, Journal of Hydrology, 476, 265273.

Cloke, H. L., C. Jeffers, F. Wetterhall, T. Byrne, J. Lowe, and F. Pappenberger (2010), Climate impacts on river flow: Projections for the Medway catchment, UK, with UKCP09 and CATCHMOD, Hydrological Processes, 24(24), 3476-3489. doi: 10.1002/hyp.7769.

COGEBY (2010), Portrait du bassin versant de la rivière Yamaska., 227 pp, Conseil de gestion du bassin versant de la Yamaska (COGEBY).

Côté, B., R. Leconte, and M. Trudel (2013), Développement d'un prototype de système d'alerte aux faibles débits et aux prélèvements excessifs dans le bassin versant pilote de la rivière Yamaska, $111 \mathrm{pp}$, Université de Sherbrooke.

Cunderlik, J. M., and D. H. Burn (2004), Linkages between regional trends in monthly maximum flows and selected climatic variables, Journal of Hydrologic Engineering, 9(4), 246256. doi: 10.1061/(ASCE)1084-0699(2004)9:4(246).

Cunderlik, J. M., and S. P. Simonovic (2005), Erratum: Hydrological extremes in a southwestern Ontario river basin under future climate conditions (Hydrological Sciences Journal vol. 50 (4) (631-654)), Hydrological Sciences Journal, 50(6), 1175.

Curtis, K. E. (2006), Determining th Hydrologic Seasons and Creating a Numerical Model of the Belgrad Lakes Watershed, Colby College.

de Elia, R., and H. Côté (2010), Climate and climate change sensitivity to model configuration in the Canadian RCM over North America, Meteorol. Z., 19(4), 325-339.

de Wit, M. J. M., B. vand de Hurk, P. M. M. Warmerdam, P. J. J. F. Torfs, E. Roulin, and W. P. A. van Deursen (2007), Impact of climate change on low-flows in the river Meuse, Climatic Change(82), 351-372.

Deo, R. C., H.-R. Byun, J. F. Adamowski, and K. Begum (2016), Application of effective drought index for quantification of meteorological drought events: a case study in Australia, Theoretical and Applied Climatology, 1-21. doi: 10.1007/s00704-015-1706-5.

Dobler, C., S. Hagemann, R. L. Wilby, and J. Stötter (2012), Quantifying different sources of uncertainty in hydrological projections in an Alpine watershed, Hydrol. Earth Syst. Sci., 16(11), 4343-4360. doi: 10.5194/hess-16-4343-2012.

Douglas, E. M., R. M. Vogel, and C. N. Kroll (2000), Trends in floods and low flows in the United States: Impact of spatial correlation, Journal of Hydrology, 240(1-2), 90-105. doi: $10.1016 /$ S0022-1694(00)00336-X. 
Ehsanzadeh, E., and K. Adamowski (2007), Detection of trends in low flows across Canada, Canadian Water Resources Journal, 32(4), 251-264.

949 Engeland, K., and H. Hisdal (2009), A comparison of low flow estimates in ungauged catchments using regional regression and the HBV-model, Water Resources Management, 23(12), 2567-2586.

952 Environnement Canada. 2010. Données - Centre canadien de la modélisation et de l'analyse 953 climatique. http://www.cccma.ec.gc.ca/french/data/crcm423/crcm423 aev sresa2.shtml\#ref 954 (accessed 15 September 2013).

955 956

957

958

959

960

961

962

963

964

965

966

967

968

969

970

971

972

973

Falcone, J. (2011), GAGES-II: Geospatial Attributes of Gages for Evaluating Streamflow, edited by U. S. G. Survey, Reston, Virginia.

Fiala, T., T. B. M. J. Ouarda, and J. Hladný (2010), Evolution of low flows in the Czech Republic, Journal of Hydrology, 393(3), 206-218. doi: http://dx.doi.org/10.1016/i.jhydrol.2010.08.018.

Fortin, J.-P., R. Turcotte, S. Massicotte, R. Moussa, J. Fitzback, and J.-P. Villeneuve (2001), A distributed watershed model compatible with remote sensing and GIS data. Part I: Description of the model, Journal of Hydrologic Engineering, 6(2), 91-99.

Fossey, M., and A. N. Rousseau (2016a), Can isolated and riparian wetlands mitigate the impact of climate change on watershed hydrology? A case study approach, Journal of Environmental Management. doi: http://dx.doi.org/10.1016/j.jenvman.2016.09.043.

Fossey, M., and A. N. Rousseau (2016b), Assessing the long-term hydrological services provided by wetlands under changing climate conditions: A case study approach of a Canadian watershed, Journal of Hydrology, 541, Part B, 1287-1302. doi: 10.1016/j.jhydrol.2016.08.032.

Ge, S., D. Yang, and D. L. Kane (2012), Yukon River Basin long-term (1977-2006) hydrologic and climatic analysis, Hydrological Processes, 27(17), 2475-2484.

Giddings, L., M. Soto, B. M. Rutherford, and A. Maarouf (2005), Standardized precipitation index zones for México, Atmosfera, 18(1), 33-56.

Gilbert, R. O. (1987), Satistical Methods for Environmental Pollution Monitoring, NY.

Girard, G. (1970), Un modèle mathématique pour crues de fonte de neige et son application au Québec, Cahiers ORSTOM. Série Hydrologie, 7(1), 3-36.

Gleckler, P. J., K. E. Taylor, and C. Doutriaux (2008), Performance metrics for climate models, Journal of Geophysical Research: Atmospheres, 113(D6), n/a-n/a. doi: 10.1029/2007JD008972.

Grillakis, M. G., A. G. Koutroulis, and I. K. Tsanis (2011), Climate change impact on the hydrology of Spencer Creek watershed in Southern Ontario, Canada, Journal of Hydrology, 409(1), 1-19. doi: http://dx.doi.org/10.1016/j.jhydrol.2011.06.018.

Guay, C., M. Minville, and M. Braun (2015), A global portrait of hydrological changes at the 2050 horizon for the province of Québec, Canadian Water Resources Journal / Revue canadienne des ressources hydriques, 40(3), 285-302. doi: 10.1080/07011784.2015.1043583. 
Hagedorn, R., F. J. Doblas-Reyes, and T. N. Palmer (2005), The rationale behind the success of multi-model ensembles in seasonal forecasting - I. Basic concept, Tellus A, 57(3), 219-233. doi: 10.1111/j.1600-0870.2005.00103.x.

Hamed, K. H., and A. RamachandraRao (1998), A Modified Mann-Kendall Test for Autocorrelated Data, Journal of Hydrology, 204(1-4). doi: 10.1016/s0022-1694(97)00125-x.

Hartigan, J. A., and M. A. Wong (1979), Algorithm AS 136: A K-Means Clustering Algorithm, Journal of the Royal Statistical Society. Series C (Applied Statistics), 28(1), 100-108. doi: $10.2307 / 2346830$.

Hawkins, E., and R. Sutton (2011), The potential to narrow uncertainty in projections of regional precipitation change, Climate Dynamics, 37(1), 407-418. doi: 10.1007/s00382-0100810-6.

Heddinghaus, T. R., and P. Sabol (1991), A Review of the Palmer Drought Severity Index and Where Do We Go from Here?, paper presented at Proc. 7th Conf. On Applied Climatol, September 10-13, American Meteorological Society, Boston, Massachusetts.

Hill, A. B. (1965), The Environment and Disease: Association or Causation?, Proceedings of the Royal Society of Medicine, 58(5), 295-300.

Hodgkins, G. A., R. W. Dudley, and T. G. Huntington (2005), Summer low flows in New England during the 20th Century, Journal of the American Water Resources Association, 41(2), 403-412.

Huang, X., J. Zhao, W. Li, and H. Jiang (2014), Impact of climatic change on streamflow in the upper reaches of the Minjiang River, China, Hydrological Sciences Journal, 59(1), 154164. doi: 10.1080/02626667.2013.853878.

Huard, D. (2010), Tributaires du St-Laurent - Documentation Release 0.2, 17 pp, Ouranos.

Hutchinson, M. F., D. W. McKenney, K. Lawrence, J. H. Pedlar, R. F. Hopkinson, E. Milewska, and P. Papadopol (2009), Development and testing of Canada-wide interpolated spatial models of daily minimum-maximum temperature and precipitation for 1961-2003, Journal of Applied Meteorology and Climatology, 48(4), 725-741.

Institution Adour (2011), Suivi des étiages 2010 et 2011 - Evolution interannuelle 2003-2011, $130 \mathrm{pp}$, Institution Adour.

IPCC. 2013. Definition of Terms Used Within the DDC Pages. http://www.ipccdata.org/guidelines/pages/definitions.html (accessed December 2015).

Jiménez Cisneros, B. E., T. Oki, N. W. Arnell, G. Benito, J. G. Cogley, P. Doll, T. Jiang, and S. S. Mwakalila (2014), Freshwater resources, in Climate Change 2014: Impacts, Adaptation, and Vulnerability. Part A: Global and Sectoral Aspects. Contribution of Working Group II to the Fifth Assessment Report of the Intergovernmental Panel on Climate Change, edited by C. B. Field, et al., pp. 229-269, Cambridge, United Kingdom

and New York, NY, USA.

Karyn, T., and J. W. Williams (2010), Globally downscaled climate projections for assessing the conservation impacts of climate change, Ecological Applications, 20(2), 554-565. doi: 10.1890/09-0173.1. 
1027

1028

1029

1030

1031

1032

1033

1034

1035

1036

1037

1038

1039

1040

1041

1042

1043

1044

1045

1046

1047

1048

1049

1050

1051

1052

1053

1054

1055

1056

1057

1058

1059

1060

1061

1062

1063

1064

1065

1066

Kendall, M. G. (1938), A New Measure of Rank Correlation, Biometrika, 30(1/2), 81-93. doi: $10.2307 / 2332226$.

Kendall, M. G. (1975), Rank Correlation Methods, 4th edition ed., Charles Griffin, London.

Khaliq, M. N., T. B. M. J. Ouarda, and P. Gachon (2009), Identification of temporal trends in annual and seasonal low flows occurring in Canadian rivers: The effect of short- and longterm persistence, Journal of Hydrology, 369(1), 183-197. doi: http://dx.doi.org/10.1016/i.jhydrol.2009.02.045.

Khattak, M. S., M. S. Babel, and M. Sharif (2011), Hydro-meteorological trends in the upper Indus River basin in Pakistan, Climate Research, 46(2), 103-119. doi: 10.3354/cr00957.

Kingston, D. G., J. R. Thompson, and G. Kite (2011), Uncertainty in climate change projections of discharge for the Mekong River Basin, Hydrol. Earth Syst. Sci., 15(5), 14591471. doi: 10.5194/hess-15-1459-2011.

Klein, I. M., A. N. Rousseau, A. Frigon, D. Freudiger, and P. Gagnon (2016), Development of a methodology to evaluate probable maximum snow accumulation (PMSA) under changing climate conditions: Application to southern Queec, Journal of Hydrology. doi: 10.1016/j.jhydrol.2016.03.031.

Kour, R., N. Patel, and A. P. Krishna (2016), Assessment of temporal dynamics of snow cover and its validation with hydro-meteorological data in parts of Chenab Basin, western Himalayas, Science China Earth Sciences, 59(5), 1081-1094. doi: 10.1007/s11430-0155243-y.

Krause, P., D. P. Boyle, and F. Bäse (2005), Comparison of different efficiency criteria for hydrological model assessment, Adv. Geosci., 5, 89-97. doi: 10.5194/adgeo-5-89-2005.

Labbé, J., R. Fournier, and J. Théau (2011), Documentation et sélection des bassins versants à l'étude, 84 pp, Université de Sherbrooke.

Lambert, S. J., and G. J. Boer (2001), CMIP1 evaluation and intercomparison of coupled climate models, Climate Dynamics, 17(2), 83-106. doi: 10.1007/p100013736.

Lang Delus, C., A. Freyeruth, E. Gille, and D. François (2006), Le dispositif PRESAGES (PREvisions et Simulations pour l'Annonce et la Gestion des Etiages Sévères) : des outils pour évaluer et prévoir les étiages, Géocarrefour, 81(1), 15-24.

Lettenmaier, D. P., E. F. Wood, and J. R. Wallis (1994), Hydro-climatological trends in the continental United States, Journal of Climate(7), 586-607.

Li, F., G. Zhang, and Y. J. Xu (2014), Spatiotemporal variability of climate and streamflow in the Songhua River Basin, northeast China, Journal of Hydrology, 514, 53-64. doi: 10.1016/j.jhydrol.2014.04.010.

Li, Z., W. Z. Liu, X. C. Zhang, and F. L. Zheng (2009), Impacts of land use change and climate variability on hydrology in an agricultural catchment on the Loess Plateau of China, Journal of Hydrology, 377(1-2), 35-42. doi: 10.1016/j.jhydrol.2009.08.007.

Ling, H., H. Xu, and J. Fu (2013), High- and low-flow variations in annual runoff and their response to climate change in the headstreams of the Tarim River, Xinjiang, China, Hydrological Processes, 27(7), 975-988. doi: 10.1002/hyp.9274. 
Liu, L., Y. Hong, C. N. Bednarczyk, B. Yong, M. A. Shafer, R. Riley, and J. E. Hocker (2012), Hydro-Climatological Drought Analyses and Projections Using Meteorological and Hydrological Drought Indices: A Case Study in Blue River Basin, Oklahoma, Water Resources Management, 26(10), 2761-2779.

Livezey, R. E., and W. Y. Chen (1983), Statistical Field Significance and its Determination by Monte Carlo Techniques, Monthly Weather Review, 111(1), 46-59. doi: 10.1175/15200493(1983)111<0046:sfsaid>2.0.co;2.

1076

1077

1078

1079

1080

1081

1082

1083

1084

1085

1086

1087

1088

1089

1090

1091

1092

1093

1094

1095

1096

1097

1098

1099

1100

1101

1102

1103

1104

1105

1106

1107

1108

Lopez, A., F. Fung, M. New, G. Watts, A. Weston, and R. L. Wilby (2009), From climate model ensembles to climate change impacts and adaptation: A case study of water resource management in the southwest of England, Water Resources Research, 45(8). doi: 10.1029/2008WR007499.

Mann, H. B. (1945), Nonparametric tests against trend, Econometrica, 13(3), 245-259.

Mann, H. B., and D. R. Whitney (1947), On a Test of Whether one of Two Random Variables is Stochastically Larger than the Other, Ann. Math. Statist., 18(1), 50-60. doi: 10.1214/aoms/1177730491.

Masih, I., S. Uhlenbrook, S. Maskey, and V. Smakhtin (2011), Streamflow trends and climate linkages in the Zagros Mountains, Iran, Climatic Change, 104(2), 317-338. doi: 10.1007/s10584-009-9793-x.

Mavrommatis, T., and K. Voudouris (2007), Relationships between hydrological parameters using correlation and trend analysis, Creteisland, Greece, Journal of Environmental Hydrology, 15, 1-13.

McKee, T. B., N. J. Doeskin, and J. Kleist (1993), The relationship of drought frequency and duration to time scales, paper presented at Proc. 8th Conf. on Applied Climatology, January 17-22, American Meteorological Society, Boston, Massachusetts,.

McKee, T. B., N. J. Doeskin, and J. Kleist (1995), Drought monitoring with multiple time scales, paper presented at Proc. 9th Conf. on Applied Climatology, January 15-20, American Meteorological Society, Boston, Massachusetts.

MDDELCC (2015), Guide de conception des installations de production d'eau potable, 559 $\mathrm{pp}$, minsitère du Développement durable, de l'Environnement et de la Lutte contre les changements climatiques Québec.

MDDEP. 2007. Calcul et interprétation des objectifs environnementaux de rejet pour les contaminants en milieu aquatique (2e édition). Québec, ministère du Développement durable, de l'Environnement et des Parcs, Direction du suivi de l'état de l'environnement,. http://www.mddelcc.gouv.qc.ca/eau/oer/Calcul interpretation OER.pdf (accessed Octobre 2017).

Mearns, L. O., et al. (2012), The North American Regional Climate Change Assessment Program: Overview of Phase I Results, Bulletin of the American Meteorological Society, 93(9), 1337-1362. doi: 10.1175/BAMS-D-11-00223.1.

Meehl, G. A., C. Covey, K. E. Taylor, T. Delworth, R. J. Stouffer, M. Latif, B. McAvaney, and J. F. B. Mitchell (2007a), THE WCRP CMIP3 Multimodel Dataset: A New Era in Climate 

10.1175/BAMS-88-9-1383.

1111

1112

1113

1114

1115

1116

1117

1118

1119

1120

1121

1122

1123

1124

1125

1126

1127

1128

1129

1130

1131

1132

1133

1134

1135

1136

1137

1138

1139

1140

1141

1142

1143

1144

1145

1146

1147

1148

1149

1150

Meehl, G. A., T. F. Stocker, W. D. Collins, P. Friedlingstein, A. T. Gaye, J. M. Gregory, A. Kitoh, R. Knutti, J. M. Murphy, A. Noda, S. C. B. Raper, I. G. Watterson, A. J. Weaver, and Z.-C. Zhao (2007b), Global Climate Projections, in Climate Change 2007: The Physical Science Basis. Contribution of Working Group I to the Fourth Assessment Report of the Intergovernmental Panel on Climate Change, edited by S. Solomon, D. Qin, M. Manning, Z. Chen, M. Marquis, K. B. Averyt, M. Tignor and H. L. Miller, Cambridge University Press, Cambridge, United Kingdom and New York, NY, USA.

Minville, M., F. Brissette, and R. Leconte (2008), Uncertainty of the impact of climate change on the hydrology of a nordic watershed, Journal of Hydrology, 358(1), 70-83. doi: http://dx.doi.org/10.1016/j.jhydrol.2008.05.033.

Mishra, A. K., and V. P. Singh (2010), A review of drought concepts, Journal of Hydrology, 391(1-2), 202-216.

Moriasi, D. N., J. G. Arnold, M. W. VanLiew, R. L. Bingner, R. D. Harmel, and T. L. Veith (2007), Model evaluation guidelines for systematic quantification of accuracy in watershed simulations, Transactions of the ASABE, 50(3), 885-900.

Morin, P., and F. Boulanger (2005), Portrait de l'environnement du bassin versant de la rivière Bécancour, 197 pp, Envir-Action pour le Groupe de concertation du bassin de la rivière Bécancour (GROBEC), Plessiville, Québec, Canada.

Mpelasoka, F. S., and F. H. S. Chiew (2009), Influence of rainfall scenario construction methods on runoff projections, Journal of Hydrometeorology, 10, 1168-1183. doi: 10.1175/2009JHM1045.1.

Music, B., and D. Caya (2007), Evaluation of the Hydrological Cycle over the Mississippi River Basin as Simulated by the Canadian Regional Climate Model (CRCM), Journal of Hydrometeorology, 8(5), 969-988. doi: 10.1175/JHM627.1.

Nakicenovic, N., R. Swart, and et al. (2000), IPCC special report on emissions scenarios : a special report of Working Group III of the IPCC, 599 pp, Cambridge, UK.

Noël, P., A. N. Rousseau, C. Paniconi, and D. F. Nadeau (2014), An algorithm for delineating and extracting hillslopes and hillslope width functions from gridded elevation data, Journal of Hydrologic Engineering, 19(2), 366-374. doi: 10.1061/(ASCE)HE.1943-5584.0000783.

Novotny, E. V., and H. G. Stefan (2007), Streamflow in Minnesota: Indicator of climate change, Journal of Hydrology, 334(3-4), 319-333. doi: 10.1016/j.jhydrol.2006.10.011.

Palmer, T. N., et al. (2004), DEVELOPMENT OF A EUROPEAN MULTIMODEL ENSEMBLE SYSTEM FOR SEASONAL-TO-INTERANNUAL PREDICTION (DEMETER), Bulletin of the American Meteorological Society, 85(6), 853-872. doi: 10.1175/bams-85-6-853.

Palmer, W. (1965), Meteorological Drught, Research paper, 58 pp, US weather Bureau, Washinghtonm DC.

Paltineanu, C., I. F. Mihailescu, I. Seceleanu, C. Dragota, and F. Vasenciuc (2007), Using aridity indexes to describe some climate and soil features in Eastern Europe: a Romanian case study, Theoretical and Applied Climatology, 90(3-4), 263-274. doi: 10.1007/s00704007-0295-3. 
Paltineanu, C., I. F. Mihailescu, Z. Prefac, C. Dragota, F. Vasenciuc, and N. Claudia (2009), Combining the standardized precipitation index and climatic water deficit in characterizing droughts: A case study in Romania, Theoretical and Applied Climatology, 97(3-4), 219-233.

Paquin, D. (2010), Evaluation du MRCC4 en passé récent (1961-1999), Ouranos, Equipe Simulations climatiques.

PCMDI. 2016. CMIP5 Coupled Model Intercomparison Project. http://cmippcmdi.Inl.gov/cmip5/ (accessed January 2016).

Poirier, C., T. C. Fortier Filion, R. Turcotte, and P. Lacombe (2012), Apports verticaux journaliers estimés de 1900 à 2010, Centre d'expertise hydrique du Québec (CEHQ), Direction de l'expertise hydrique, Québec.

Randall, D. A., R. A. Wood, S. Bony, R. Colman, T. Fichefet, J. Fyfe, V. Kattsov, A. Pitman, J. Shukla, J. Srinivasan, S. R. J., A. Sumi, and K. E. Taylor (2007), Climate models and their evaluation, in Climate Change 2007: The Physical Science Basis. Contribution of Working Group 1 to the Fourth Assessment Report of the Intergovernmental Panel on Climate Change, edited by S. Solomon, D. Qin, M. Manning, M. Chen, M. Marguis, K. B. Averyt, M. Tignor and H. L. Miller, pp. 589-662, Cambridge University Press, Cambridge, UK.

Raupach, M. R., G. Marland, P. Ciais, C. Le Quéré, J. G. Canadell, G. Klepper, and C. B. Field (2007), Global and regional drivers of accelerating $\mathrm{CO}<\mathrm{inf}>2<$ inf $>$ emissions, Proceedings of the National Academy of Sciences of the United States of America, 104(24), 10288-10293. doi: 10.1073/pnas.0700609104.

Renard, B., M. Lang, P. Bois, A. Dupeyrat, O. Mestre, H. Niel, E. Sauquet, C. Prudhomme, S. Parey, E. Paquet, L. Neppel, and J. Gailhard (2008), Regional methods for trend detection: Assessing field significance and regional consistency, Water Resources Research, 44(8), n/a-n/a. doi: 10.1029/2007WR006268.

Ricard, S., R. Bourdillon, D. Roussel, and R. Turcotte (2013), Global calibration of distributed hydrological models for large-scale applications, Journal of Hydrologic Engineering, 18(6), 719-721.

Roudier, P. (2008), Vulnérabilité des ressources en eau superficielle d'un bassin soudanosahélien dans un contexte de changement climatique: approche par indicateurs, Master 2 Risques Naturels thesis, 94 pp, Ecole Nationale du Génie de l'Eau et de l'Environnement de Strasbourg (ENGEES).

Rousseau, A. N., S. Savary, and M. Fossey (2013), Modélisation hydrologique des milieux humides dans les basses-terres du Saint-Laurent - Activité en vulnérabilité, impacts et adaptation PACC 26, 88 pp, Institut national de la recherche scientifique, INRS-Ete, Québec, QC.

Rousseau, A. N., I. M. Klein, D. Freudiger, P. Gagnon, A. Frigon, and C. Ratté-Fortin (2014), Development of a methodology to evaluate probable maximum precipitation (PMP) under changing climate conditions: Application to southern Quebec, Canada, Journal of Hydrology, 519(PD), 3094-3109. doi: 10.1016/j.jhydrol.2014.10.053.

Rousseau, A. N., J. P. Fortin, R. Turcotte, A. Royer, S. Savary, F. Quévry, P. Noël, and C. Paniconi (2011), PHYSITEL, a specialized GIS for supporting the implementation of distributed hydrological models, Water News, Official Magazine of CWRA - Canadian Water Resources Association, 31(1), 18-20. 
Santhi, C., J. G. Arnold, J. R. Williams, W. A. Dugas, R. Srinivasan, and L. M. Hauck (2001), Validation of the SWAT model on a large river basin with point and nonpoint sources, Journal of the American Water Resources Association, 37(5), 1169-1188.

Savary, S., A. N. Rousseau, and R. Quilbé (2009), Assessing the effects of historical land cover changes on runoff and low flows using remote sensing and hydrological modeling, Journal of Hydrologic Engineering, 14(6), 575-587.

Smakhtin, V. U. (2001), Low flow hydrology: A review, Journal of Hydrology(240), 136-147.

Souvignet, M., P. Laux, J. Freer, H. Cloke, D. Q. Thinh, T. Thuc, J. Cullmann, A. Nauditt, W. A. Flügel, H. Kunstmann, and L. Ribbe (2013), Recent climatic trends and linkages to river discharge in Central Vietnam, Hydrological Processes, Early View(Published online before inclusion in an issue).

Staudinger, M., K. Stahl, J. Seibert, M. P. Clark, and L. M. Tallaksen (2011), Comparison of hydrological model structures based on recession and low flow simulations, Hydrol. Earth Syst. Sci., 15(11), 3447-3459. doi: 10.5194/hess-15-3447-2011.

Sushama, L., R. Laprise, D. Caya, A. Frigon, and M. Slivitzky (2006), Canadian RCM projected climate-change signal and its sensitivity to model errors, International Journal of Climatology, 26(15), 2141-2159. doi: 10.1002/joc.1362.

Svensson, C., W. Z. Kundzewicz, and T. Maurer (2005), Trend detection in river flow series: 2. Flood and low-flow index series / Détection de tendance dans des séries de débit fluvial: 2. Séries d'indices de crue et d'étiage, Hydrological Sciences Journal, 50(5), null-824. doi: 10.1623/hysj.2005.50.5.811.

Tallaksen, L. M., and H. A. J. Van Lanen (2004), Hydrological drought: processes and estimation methods for streamflow and groundwater, in Developments in Water Science, edited, Elsevier Science B.V. The Netherlands.

Teng, J., J. Vaze, F. H. S. Chiew, B. Wang, and J.-M. Perraud (2012), Estimating the Relative Uncertainties Sourced from GCMs and Hydrological Models in Modeling Climate Change Impact on Runoff, Journal of Hydrometeorology, 13(1), 122-139. doi: 10.1175/jhm-d11-058.1.

Tian, P., G. J. Zhao, J. Li, and K. Tian (2011), Extreme value analysis of streamflow time series in Poyang Lake Basin, China, Water Science and Engineering, 4(2), 121-132.

Trudel, M., P. L. Doucet-Généreux, R. Leconte, and B. Côté (2016), Vulnerability of water demand and aquatic habitat in the context of climate change and analysis of a no-regrets adaptation strategy: Study of the Yamaska River Basin, Canada, Journal of Hydrologic Engineering, 21(2). doi: 10.1061/(ASCE)HE.1943-5584.0001298.

Turcotte, R., A. N. Rousseau, J.-P. Fortin, and J.-P. Villeneuve (2003), Development of a process-oriented, multiple-objective, hydrological calibration strategy accounting for model structure, in Advances in Calibration of Watershed Models, edited by Q. Duan, S. Sorooshian, H. Gupta, A. N. Rousseau and R. Turcotte, pp. 153-163, American Geophysical Union (AGU), Washinghton, USA.

Turcotte, R., J. P. Fortin, A. N. Rousseau, S. Massicotte, and J. P. Villeneuve (2001), Determination of the drainage structure of a watershed using a digital elevation model and a digital river and lake network, Journal of Hydrology, 240(3-4), 225-242. 
Turcotte, R., L. G. Fortin, V. Fortin, J. P. Fortin, and J. P. Villeneuve (2007), Operational analysis of the spatial distribution and the temporal evolution of the snowpack water equivalent in southern Québec, Canada, Nordic Hydrology, 38(3), 211-234. doi: 10.2166/nh.2007.009.

Van Liew, M. W., J. G. Arnold, and J. D. Garbrecht (2003), Hydrologic simulation on agricultural watersheds: Choosing between two models, Transactions of the American Society of Agricultural Engineers, 46(6), 1539-1551.

Velázquez, J. A., J. Schmid, S. Ricard, M. J. Muerth, B. Gauvin St-Denis, M. Minville, D. Chaumont, D. Caya, R. Ludwig, and R. Turcotte (2013), An ensemble approach to assess hydrological models' contribution to uncertainties in the analysis of climate change impact on water resources, Hydrology and Earth System Sciences, 17(2), 565-578. doi: 10.5194/hess17-565-2013.

von Storch, H. (1999), Misuses of Statistical Analysis in Climate Research, in Analysis of Climate Variability: Applications of Statistical Techniques Proceedings of an Autumn School Organized by the Commission of the European Community on Elba from October 30 to November 6, 1993, edited by $\mathrm{H}$. von Storch and A. Navarra, pp. 11-26, Springer Berlin Heidelberg, Berlin, Heidelberg.

Waylen, P. R., and M. K. Woo (1987), Annual low flows generated by mixed processes, Hydrological Sciences Journal, 32(3), 371-383.

Wilby, R. L., S. P. Charles, E. Zorita, B. Timbal, P. Whetton, and L. O. Mearns (2004), Guidelines for use of Climate Scenarios developed from statistical downscaling methods, IPCC Task Group on data and scenario support for Impac and Climate Analysis (TGICA).

Wilhite, D., and M. Glantz (1985), Understanding the drought phenomenon: the role of definition, Water International(10), 111-120.

Wood, A. W., L. R. Leung, V. Sridhar, and D. P. Lettenmaier (2004), Hydrologic implications of dynamical and statistical approaches to downscaling climate model outputs, Climatic Change, 62(1-3), 189-216. doi: 10.1023/B:CLIM.0000013685.99609.9e.

Yang, D., D. L. Kane, L. Hinzman, X. Zhang, T. Zhang, and H. Ye (2002), Siberian Lena River hydrologic regime and recent change, Journal of Geophysical Research, 107(D23). doi: 10.1029/2002JD002542.

Yang, T., C.-Y. Xu, Q. Shao, X. Chen, G.-H. Lu, and Z.-C. Hao (2010), Temporal and spatial patterns of low-flow changes in the Yellow River in the last half century, Stochastic Environmental Research and Risk Assessment, 24(2), 297-309. doi: 10.1007/s00477-0090318-y.

Yue, S., and C. Y. Wang (2002), Applicability of prewhitening to eliminate the influence of serial correlation on the Mann-Kendall test, Water Resources Management, 38(6), 1068. doi: 10.1029/2001WR000861.

Zaidman, M. D., H. G. Rees, and A. R. Young (2001), Spatio-temporal development of streamflow droughts in north-west Europe, Hydrology and Earth System Sciences, 5(4), 733751.

Zhang, X., L. A. Vincent, W. D. Hogg, and A. Niitsoo (2000), Temperature and precipitation trends in Canada during the 20th century, Atmosphere - Ocean, 38(3), 395-429. 
1278 Zhang, X., K. David Harvey, W. D. Hogg, and T. R. Yuzyk (2001), Trends in Canadian

1279 streamflow, Water Resources Research, 37(4), 987-998. doi: 10.1029/2000WR900357.

1280

1281 
Figure_1.tif

Click here to download high resolution image

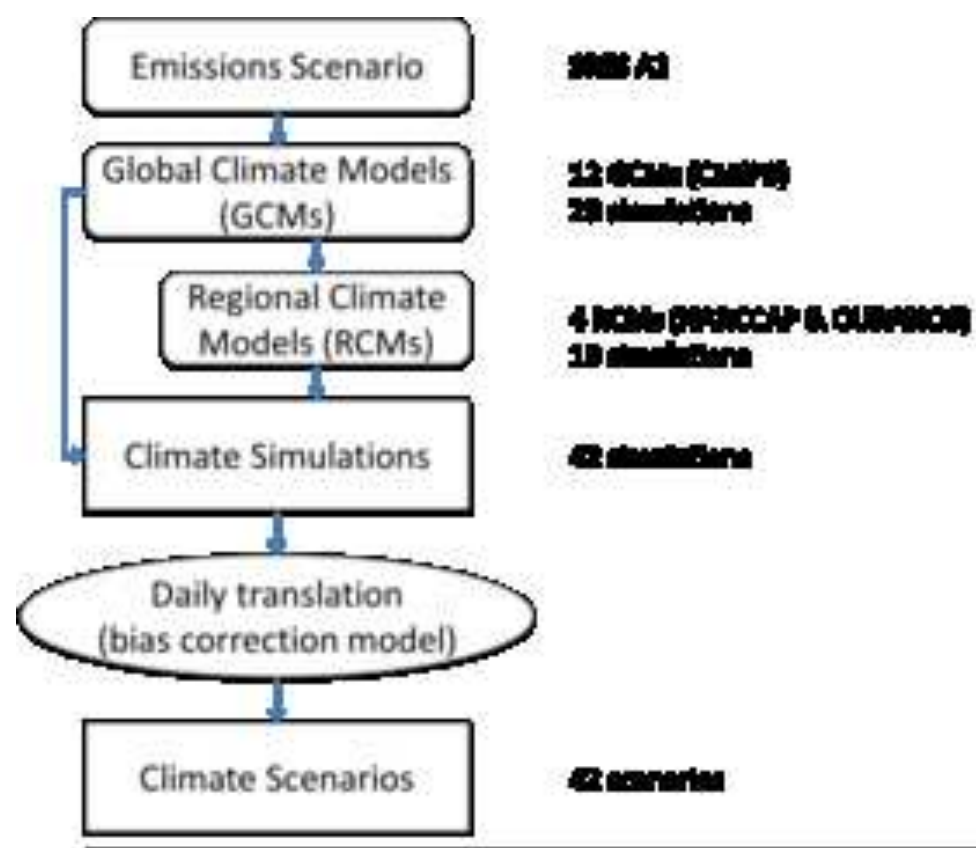

OBJECTIVE: HOW TO BYPASS THE HYOROLOGICAL MODELING STEP IN ASSESSING FUTURE HDIS?

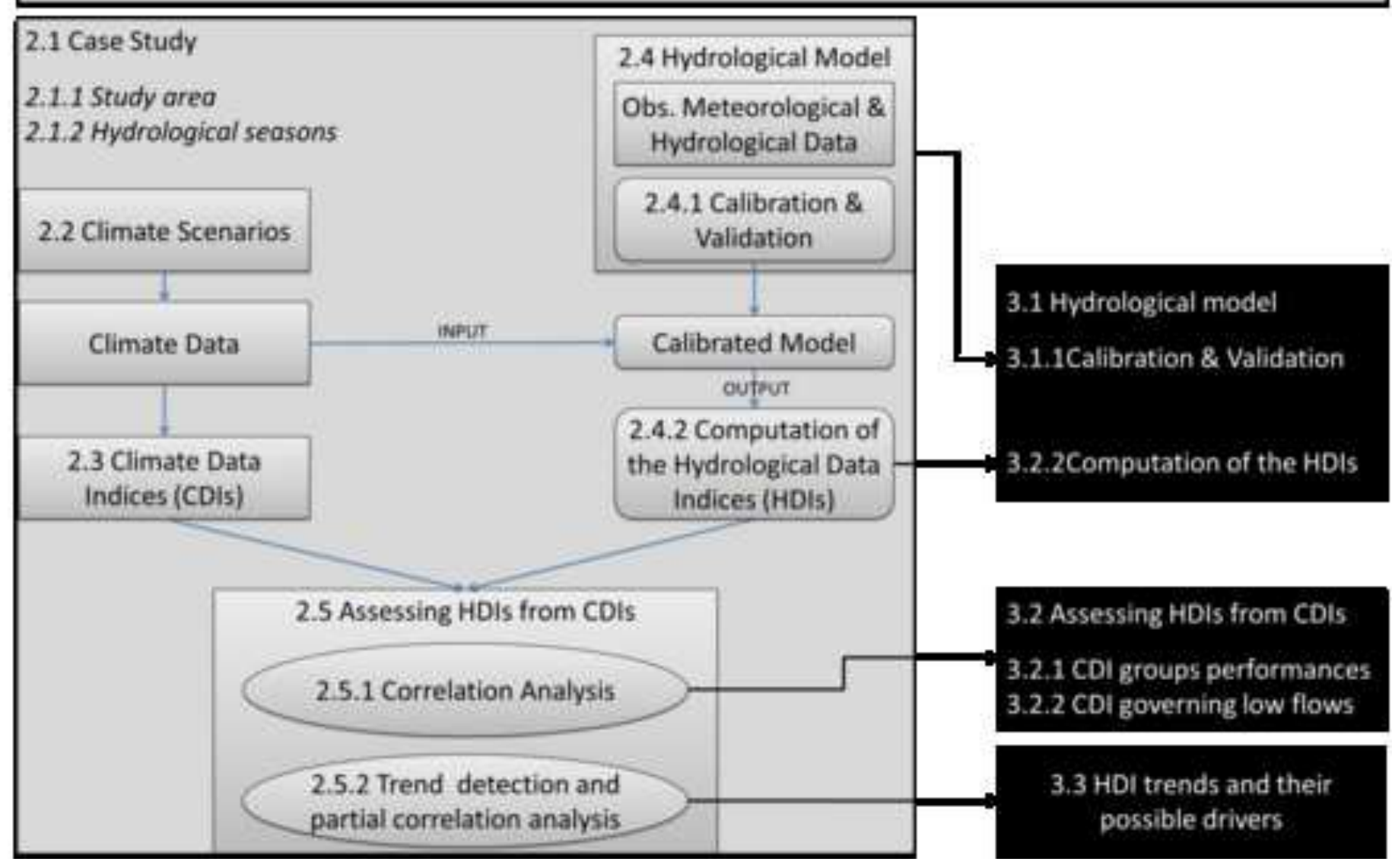


Figure captions

Figure 1: Detailed schematic of the methodological framework and mapping of the sections of this paper. White boxes stand for the computing of climate scenarios; grey boxes refer to the Material and methods section; and the black boxes refer to the Results section. 


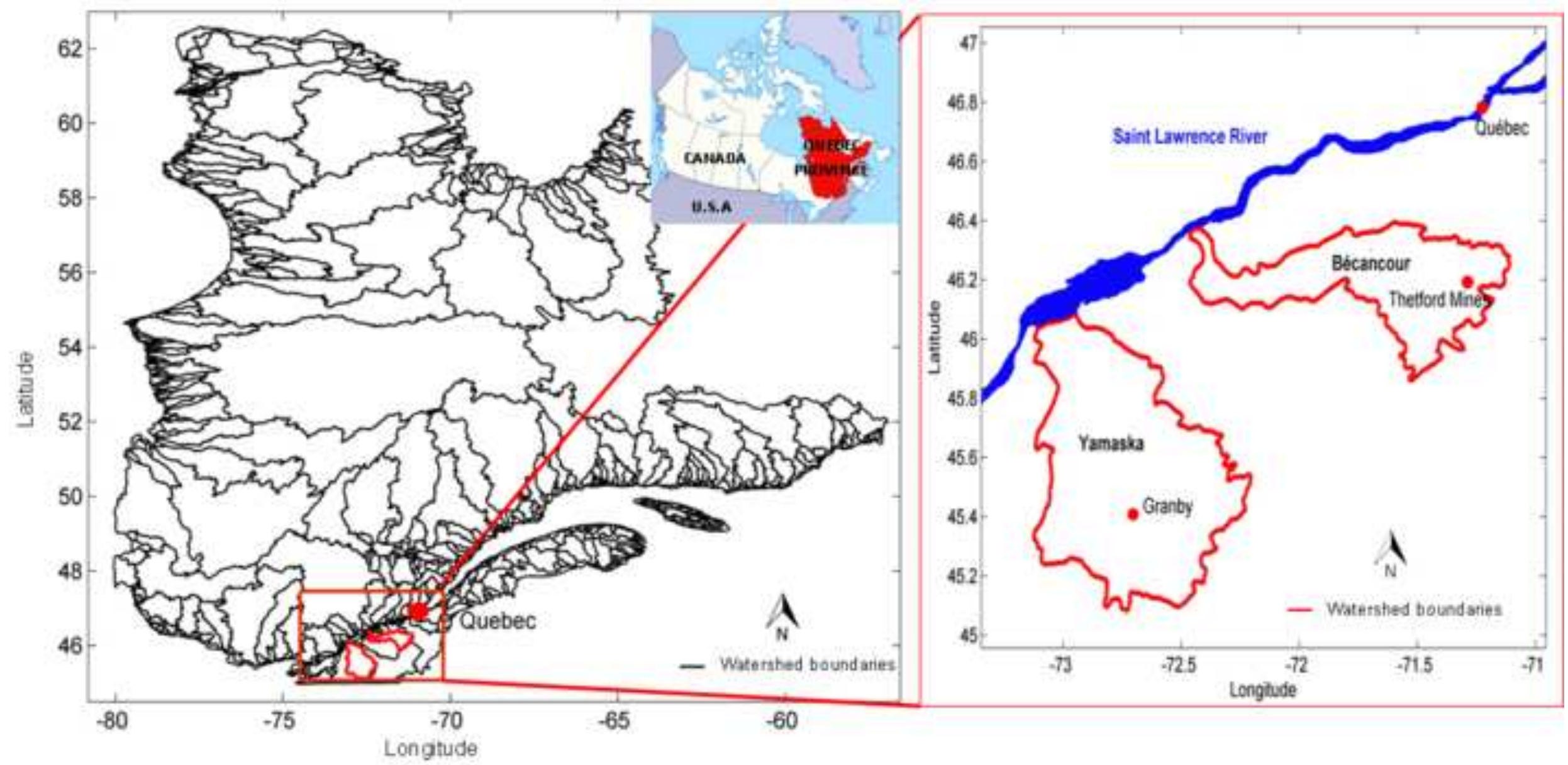




\section{Figure captions}

Figure 2: Location of the study watersheds in: (a) the province of Québec and (b) the St. Lawrence River lowlands 
Figure_3.tif

Click here to download high resolution image

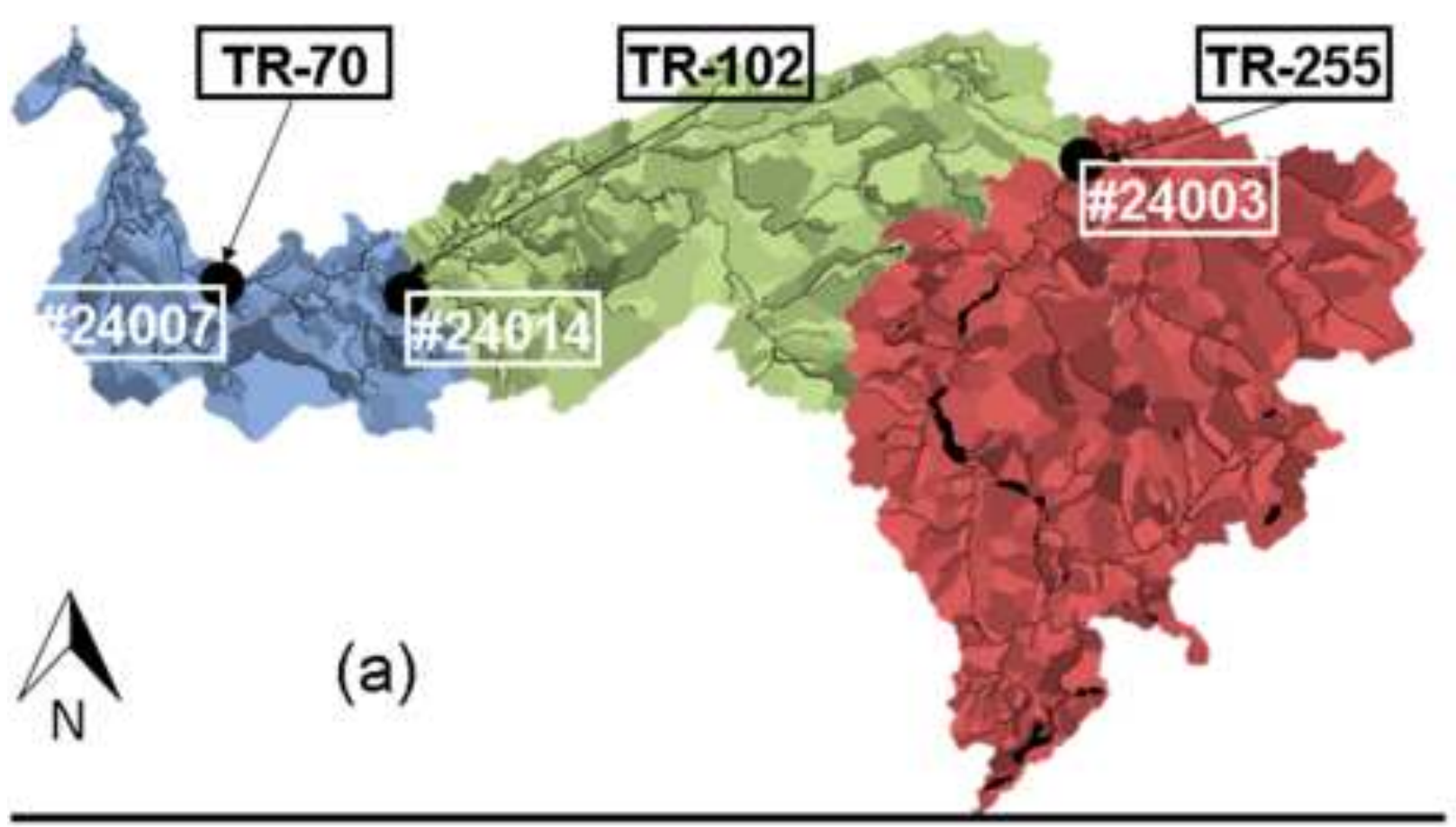

(b)

$\lambda_{N}$

- Gauging station

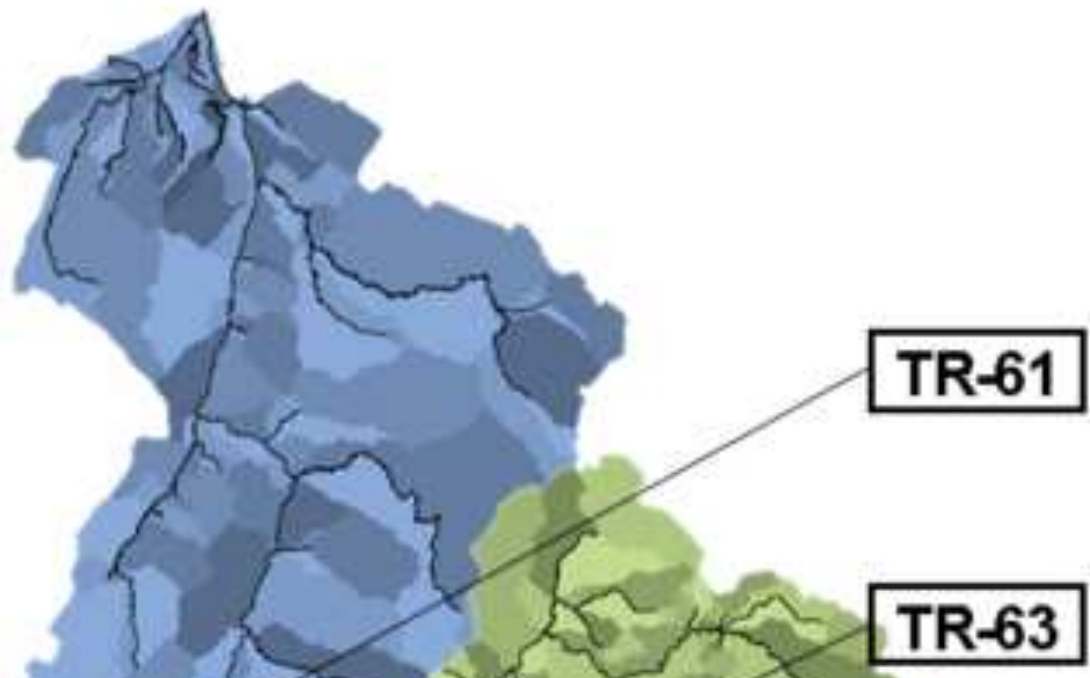

- Man made reservoir 
Figure captions

Figure 3: (a) Bécancour and (b) Yamaska parametrization regions and hydrological stations used for the calibration and validation of HYDROTEL. Red, green, and blue colors stand for upstream, median, and downstream subwatersheds, repectively. \# indicates the gauging stations reference number. 
(a)

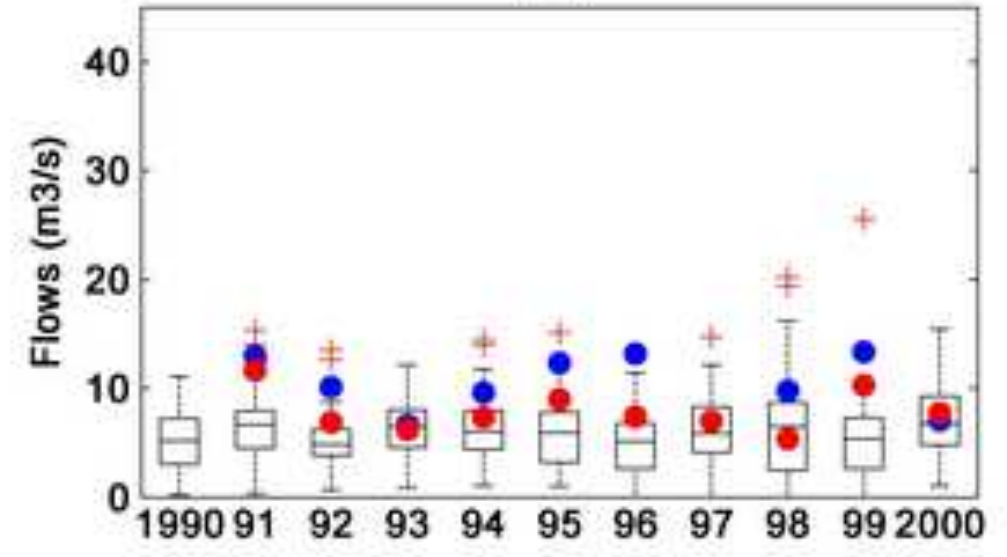

(c)

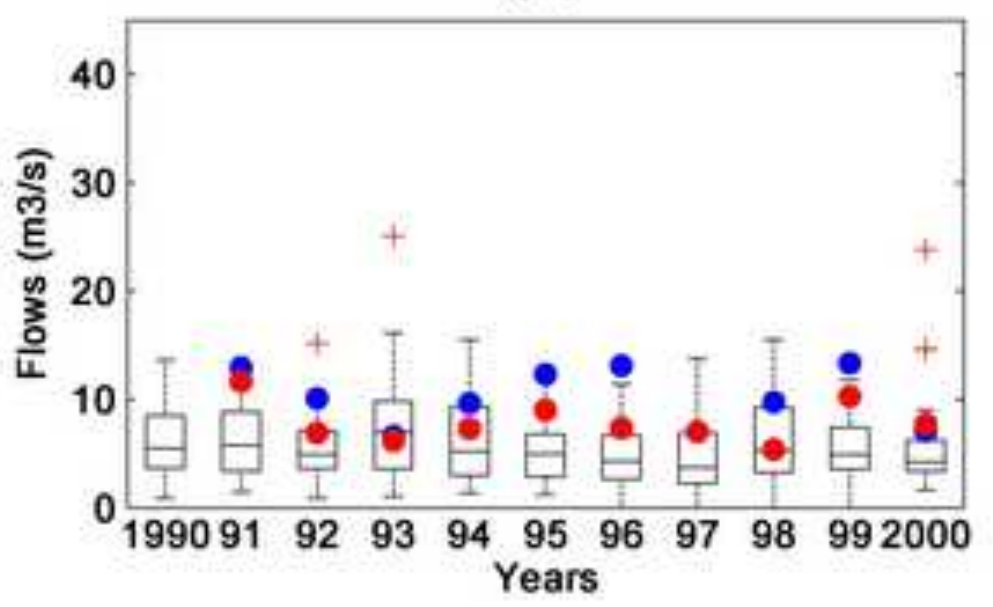

(b)

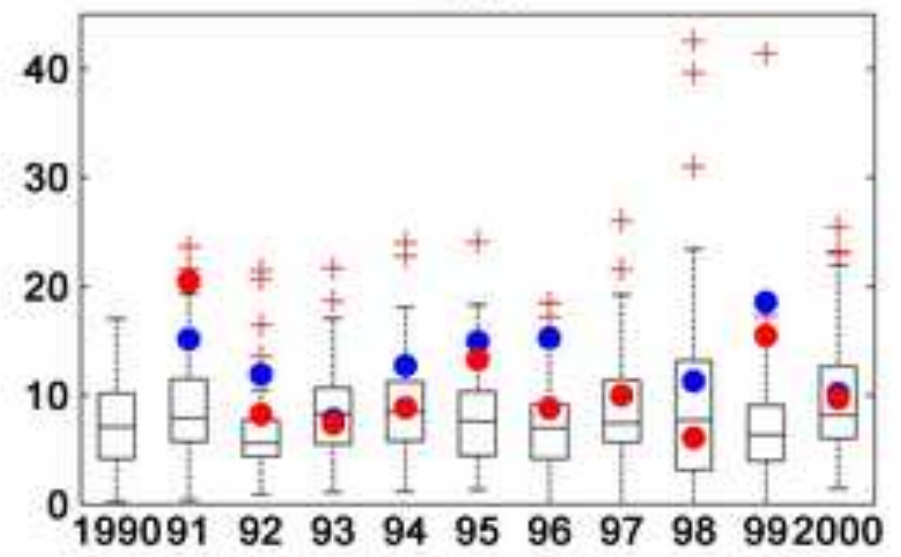

(d)

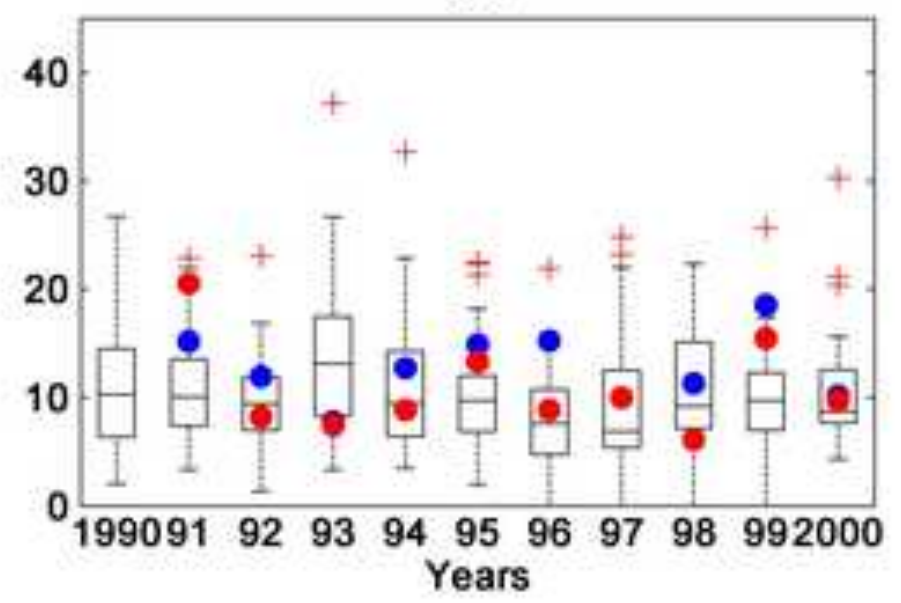


Figure captions

Figure 4: Boxplots of the HDIs computed from the modeling of the 42 climate scenarios for the Bécancour watershed: (a) SC season 7dQmin; (b) SC season 30dQmin; (c) SF season 7dQmin; and (d) SF season 30dQmin. Blue and red dots stand for the HDIs computed during the calibration/validation process from the observed and modeled flows, respectively. 
(a)

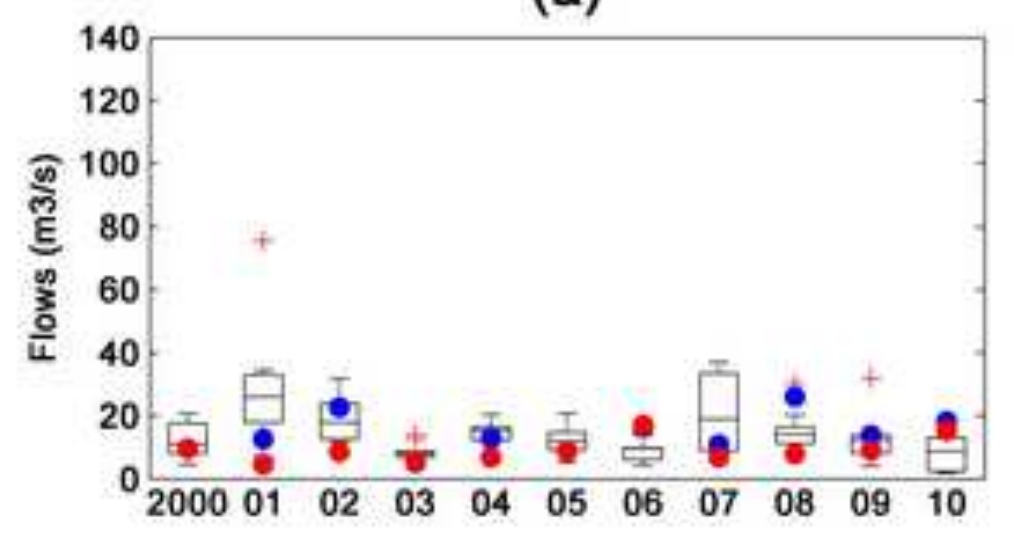

(c)

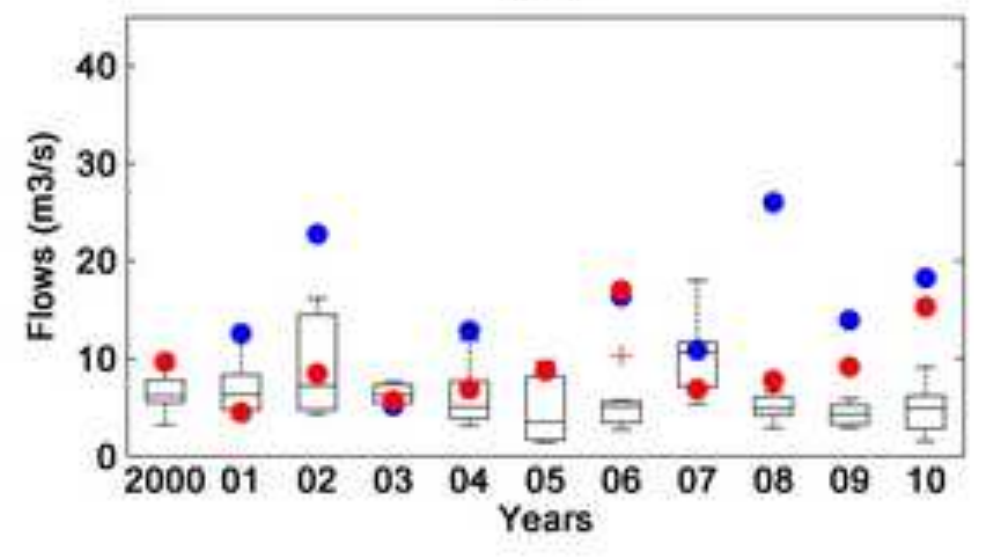

(b)

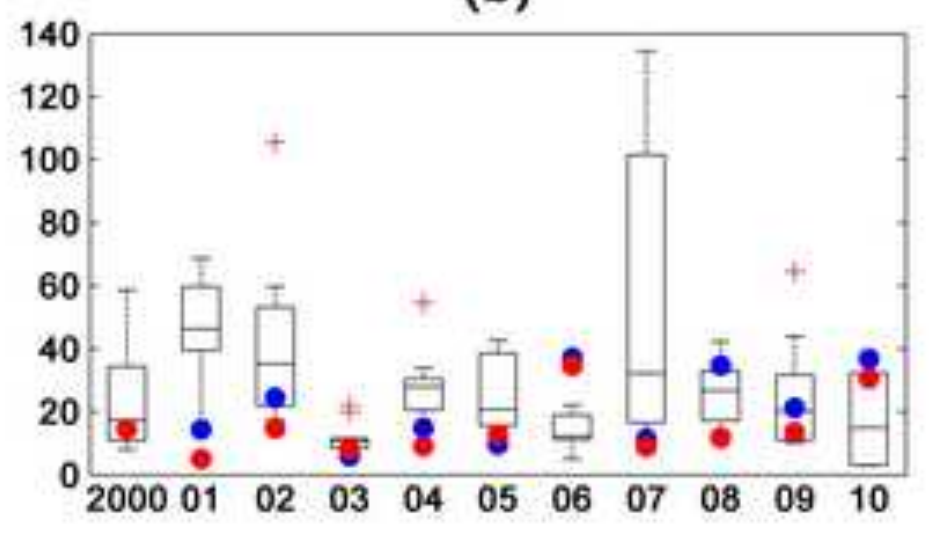

(d)

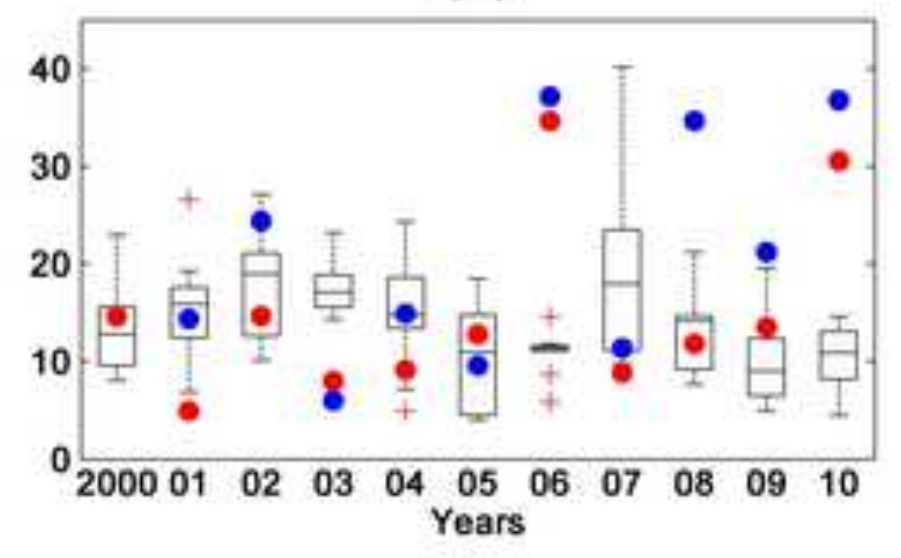


Figure captions

Figure 5: Boxplots of the HDIs computed from the modeling of the 10 Ouranos climate scenarios for the Yamaska watershed: (a) SC season 7dQmin; (b) SC season 30dQmin; (c) SF season 7dQmin; and (d) SF season 30 dQmin. Blue and red dots stand for the HDIs computed during the calibration/validation process from the observed and modeled flows, respectively. 

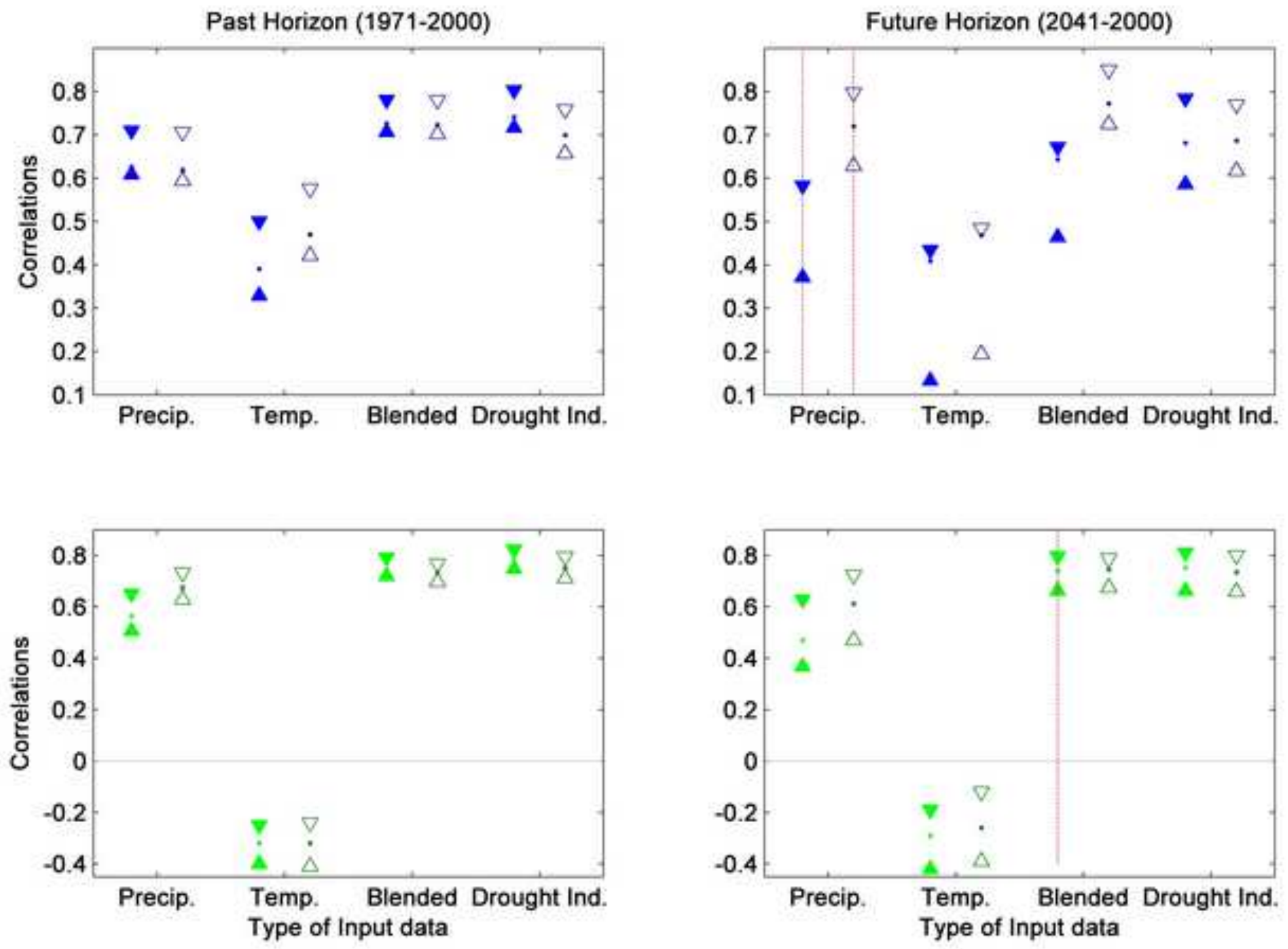


\section{Figure captions}

Figure 6: Pearson median correlations $r$ [95\% confidence interval CI] for the Bécancour watershed, for the SC (blue) and SF (green) seasons, for the 7dQmin (solid triangles) and 30dQmin (hollow triangles), and for the past (left side) and future (right side) temporal horizons. The 95\% CI was computed through Monte Carlo resampling of the 42 climate scenarios. The red dotted line stands for Wilcoxon tests that rejected the null hypothesis (median correlations are equal between past and future horizons) at the 5\% significance level. 

Supplementary material for on-line publication only
Click here to download Supplementary material for o

Click here to download Supplementary material for on-line publication only: Article1_suporting_info.doc 